\title{
Design and development of ITER high-frequency magnetic sensor
}

\author{
$\underline{\text { Y. Ma }^{1,2}}$, G. Vayakis ${ }^{1}$, L.B. Begrambekov ${ }^{3}$, J-J. Cooper ${ }^{4}$, I. Duran ${ }^{5}$, M. Hirsch ${ }^{6}$, H.P. Laqua ${ }^{6}$, Ph.

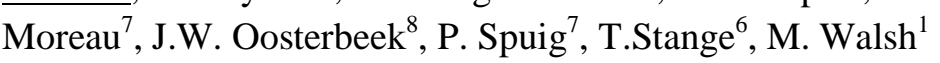 \\ 1. ITER Organization, Route de Vinon-sur-Verdon, CS 90 046, 13067 St. Paul Lez Durance Cedex - France \\ 2. Fircroft Engineering, Lingley House, 120 Birchwood Point, Birchwood Boulevard, Warrington, WA3 7QH - UK \\ 3. National Research Nuclear University (MEPhI), 115409, Moscow, Kashirskoe shosse 31 - Russia \\ 4. Culham Centre for Fusion Energy (CCFE), Abingdon, Oxfordshire OX14 3DB - UK \\ 5. IPP Prague, Za Slovankou 1782/3, 18200 Prague 8 - Czech Republic \\ 6. Max-Planck-Institut für Plasmaphysik, Teilinstitut Greifswald, Wendelsteinstraße 1, D-17491 Greifswald - Germany \\ 7. CEA Cadarache, 13108 Saint Paul lez Durance Cedex - France \\ 8. Eindhoven University of Technology (TU/e), PO Box 513, 5600 MB Eindhoven - Netherlands \\ Email: Yunxing.Ma@iter.org
}

\begin{abstract}
High-frequency (HF) inductive magnetic sensors are the primary ITER diagnostic set for Toroidal Alfvén Eigenmodes (TAE) detection, while they also supplement low-frequency MHD and plasma equilibrium measurements. These sensors will be installed on the inner surface of ITER vacuum vessel, operated in a harsh environment with considerable neutron/nuclear radiation and high thermal load. Essential components of the HF sensor system, including inductive coil, electron cyclotron heating $(\mathrm{ECH})$ shield, electrical cabling and termination load, have been designed to meet ITER measurement requirements. System performance (e.g. frequency response, thermal conduction) has been assessed. A prototyping campaign was initiated to demonstrate the manufacturability of the designed components. Prototypes have been produced according to the specifications. A series of lab tests have been performed to examine assembly issues and validate electrical and thermo-mechanical aspects of the design. In-situ microwave radiation test has been conducted in the MISTRAL test facility at IPP-Greifswald to experimentally examine the microwave shielding efficiency and structural integrity of the ECH shield. Low-power microwave attenuation measurement and scanning electron microscopic inspection were conducted to probe and examine the quality of the metal coating on the ECH shield.
\end{abstract}

\section{Content}

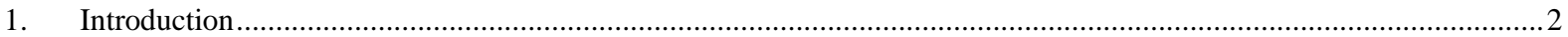

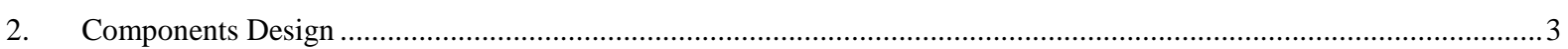

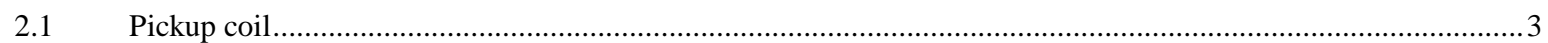

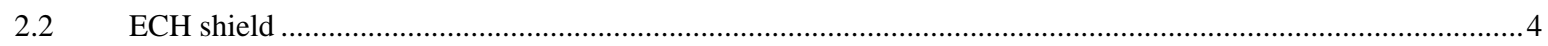

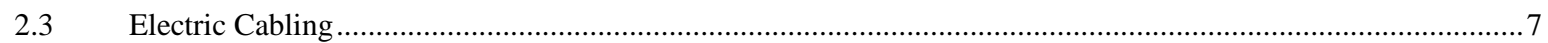

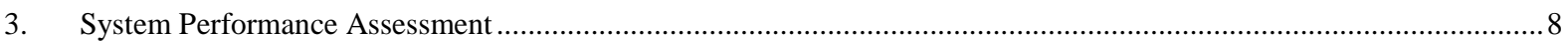

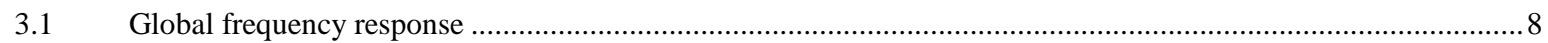

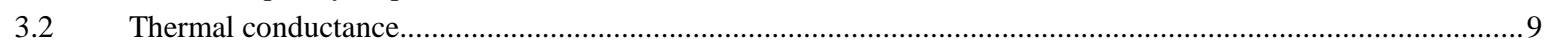

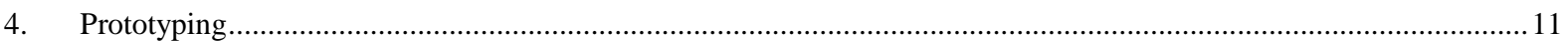

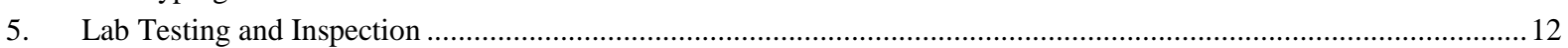

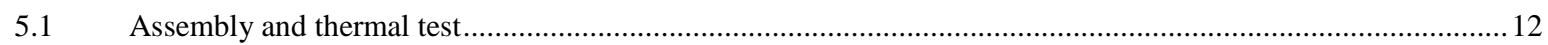

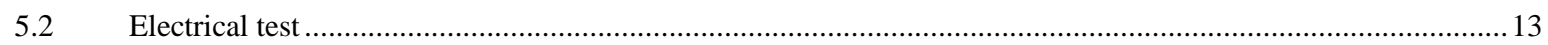

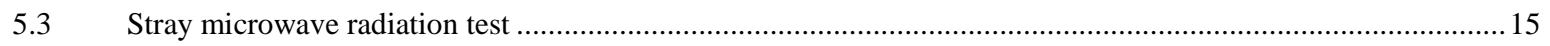

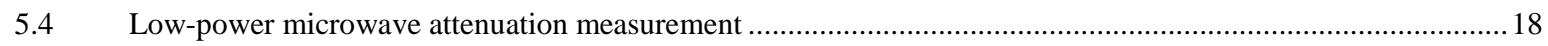

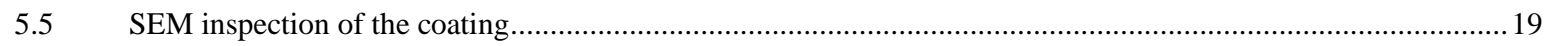

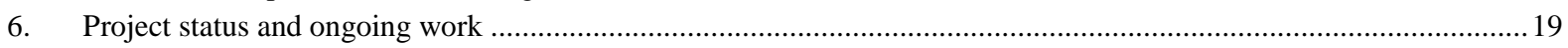

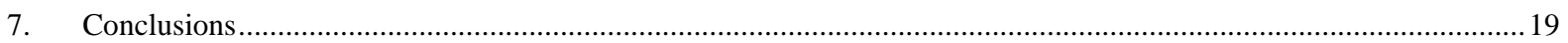

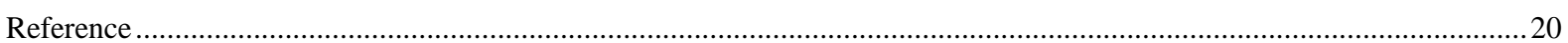

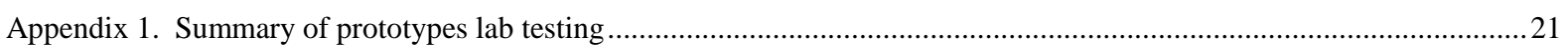

Appendix 2. Impedance measurement of HF pickup coil ........................................................................................22

Appendix 3. Frequency dependence of HF pickup coil electrical properties ..............................................................23

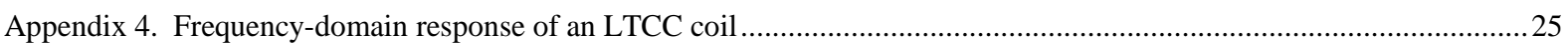




\section{Introduction}

Burning plasmas inside the ITER tokamak could generate a variety of MHD instabilities that may impact local and/or global plasma performance. Therefore, detection of these instabilities is important for ITER plasma control and operation and beneficial for fundamental physics studies aiming to better understand the underlying mechanism. The high-frequency (HF) inductive magnetic sensors (hereafter called HF sensors for simplicity) are the primary ITER diagnostic to detect toroidal Alfvén Eigenmodes (TAE) triggered by the high-energy particles generated in ITER's burning plasma core. Characteristic frequencies for the TAE of primary physics interest are expected to occur in the wide range of $30 \mathrm{kHz}-500 \mathrm{kHz}$ on ITER. In addition to the main role, HF sensors also supplement lowfrequency (below 10kHz) MHD modes detection, and serve as a backup diagnostic for plasma equilibrium measurement. To meet these needs, ITER HF sensors must be designed to operate in a broad frequency range from nearly DC up to $500 \mathrm{kHz}$. In total $209 \mathrm{HF}$ sensors will be deployed according to the current ITER tokamak design configuration. These sensors will be installed on the inner surface of the ITER Vacuum Vessel (VV). A vast majority of these sensors have the magnetic axis oriented in the poloidal direction (only about 20 sensors near the equatorial have the magnetic axis pointing in the toroidal direction).

The HF sensor system needs the following components to successfully deliver measurements:

- An inductive pickup coil to detect magnetic perturbations;

- An ECH shield covering the coil to prevent it from direct exposure to stray microwave radiation, in particular, those from electron cyclotron heating $(\mathrm{ECH})$ waves;

- A support structure, or platform, attached to the VV to provide mechanical support and heat conduction for the coil and the shield, and enable electric connection with the cabling;

- Electric Cabling to transmit the electric signals generated by the coil across the VV boundary to the data acquisition system;

○ Data acquisition (DAQ) system to collect and process the received electric signals. A schematic of the HF sensor system is shown in Figure 1.

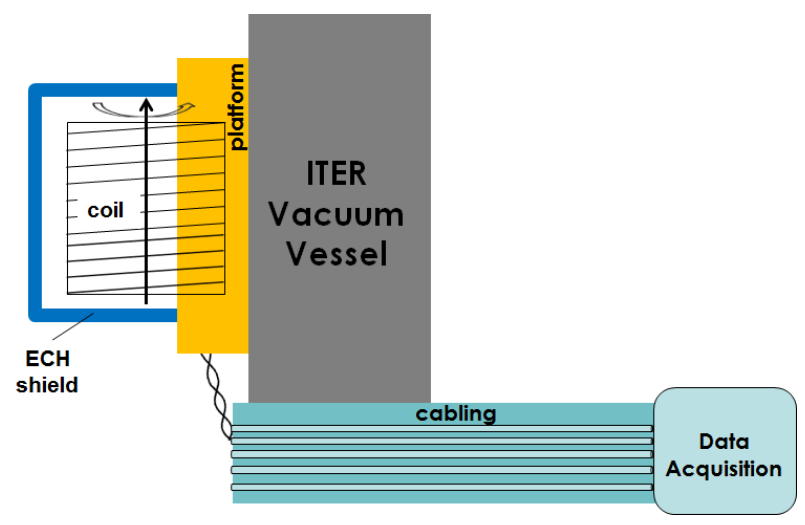

Figure 1: illustration of ITER HF sensor system comprising pickup coil, ECH shield, support platform, electrical cabling, and data acquisition

Subsequent chapters will focus on design (Chapter 2), prototyping (Chapter 4), and lab testing (Chapter 5) of the pickup coil, the ECH shield, and the electric cabling. System performance assessment of the HF sensor system is covered in Chapter 3. Design of the platform is also an important but relatively independent topic, which is beyond the scope of this paper. Some recent progress on the platform design is reported in [1]. Design of the electronics and DAQ for the HF 
sensor along with all other ITER magnetic diagnostics is undertaken under another work package. Latest progress is covered in [2].

The general design constraints for the HF sensor system from ITER system-level measurement requirements ([3]) and system design integration ([4]) are summarized in

Table 1. In addition, the design must also comply with the corresponding ITER safety and vacuum classification applicable to this system. The choice of materials should take into account changes in physical properties after neutron and nuclear radiation.

\begin{tabular}{|c|c|}
\hline coil effective area $\left(A_{\text {eff }}\right)$ & $A_{\text {eff }} \geq 0.05 \mathrm{~m}^{2}$ \\
\hline operational frequency range & $10 \mathrm{~Hz}-500 \mathrm{kHz}$ \\
\hline spatial reservation & $\begin{array}{c}\text { sensor assembly including the inductive coil, the ECH shield, and the } \\
\text { mechanical support structure, should fit into the allocated space, i.e. a } \\
\text { cube approximately } 120 \mathrm{~mm} \times 100 \mathrm{~mm} \text { when projected to ITER VV, and } \\
50 \mathrm{~mm} \text { normal to the VV surface }\end{array}$ \\
\hline
\end{tabular}

Table 1: general design constraints for ITER HF sensor system

\section{Components Design}

\subsection{Pickup coil}

The pickup coil functions according to the Faraday's law of inductance. The induced e.m.f. in the coil is given by $V_{S}=N A \dot{B}$, with $N$ the number of winding turns, $A$ the area encircled by a turn, and $\dot{B}=d B / d t$ the time derivative of the magnetic field perturbation parallel to coil's axis. The output voltage requirement $V_{s} \geq 10 \mathrm{mV}$ is translated into $A_{\text {eff }}=N A \geq 0.05 \mathrm{~m}^{2}$ for $300 \mathrm{~Hz}<f<500 \mathrm{kHz}$ with nominal magnetic perturbation amplitudes expected on ITER $\left(10^{-4} \mathrm{~T}-0.05 \mathrm{~T}\right.$ for $300 \mathrm{~Hz}<f<30 \mathrm{kHz}$, $10^{-6} \mathrm{~T}-3.5 \times 10^{-4} \mathrm{~T}$ for $\left.30 \mathrm{kHz}<f<500 \mathrm{kHz}\right)$. Moreover, the coil inductance $\left(L_{c}\right)$ needs to be minimized for high-frequency application. Note that $L_{c} \sim N^{2} A / l=A_{\text {eff }}^{2} / V$, with $l$ the axial length of the winding, and $V$ the volume enclosed by the winding. Therefore, for a given (target) $A_{\text {eff }}$, a general design principle is to maximize the volume of the coil within the available space.
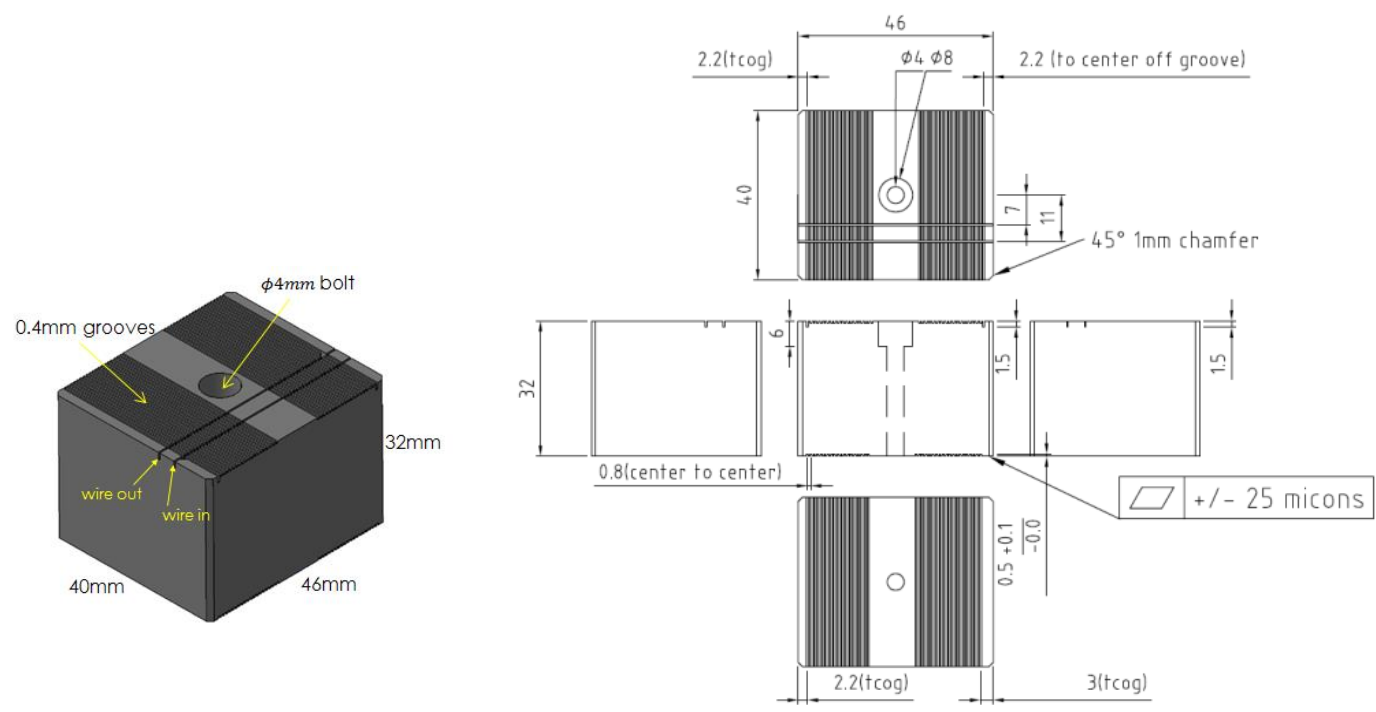

Figure 2: HF pickup coil design (left) 3D model, and (right) drawings (courtesy of CCFE). 
Design of the inductive coil is shown in Figure 2. The coil is constructed by winding a copper wire on a cubic bobbin. The top and bottom surface of the bobbin are grooved to guide and secure the winding. An M4 bolt is placed in the through hole in the center of the bobbin to fasten the coil to the underlying mounting plate (see Section 5.1).

\begin{tabular}{|c|c|c|}
\hline \multicolumn{2}{|c|}{ coil specifications } & electrical parameters (calculated) \\
\hline number of turns & $N=40 \quad(20$ per section $)$ & \multirow{10}{*}{ 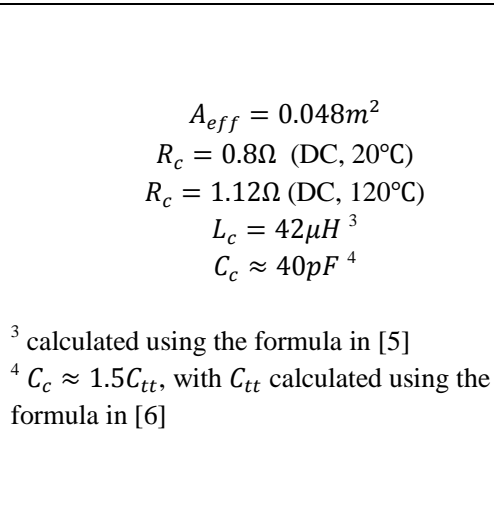 } \\
\hline wire material & $\mathrm{Cu}$ & \\
\hline coil bobbin material & $\operatorname{AlN}\left(\epsilon_{r} \approx 9.0\right)$ & \\
\hline wire diameter & $d=0.4 m m$ & \\
\hline wire resistivity & $\begin{array}{l}\rho_{C u}=1.7 \times 10^{-8} \Omega \cdot m\left(\text { at } 20^{\circ} \mathrm{C}\right) \\
\text { temperature coefficient: } 0.004 / K\end{array}$ & \\
\hline wire cross section area & $S_{w}=0.1256 \mathrm{~mm}^{2}$ & \\
\hline wire length & $l \approx 6.0 m$ & \\
\hline winding pitch $^{1}$ & $p=0.8 \mathrm{~mm}$ & \\
\hline distance of two sections ${ }^{2}$ & $d=25 \mathrm{~mm}$ & \\
\hline \multicolumn{2}{|c|}{$\begin{array}{l}{ }^{1} \text { defined as the center-center distance between two adjacent turns } \\
{ }^{2} \text { defined as the center-center distance between the two sections }\end{array}$} & \\
\hline
\end{tabular}

Table 2: (left) coil design specifications, and (right) calculated values of key electrical parameters

Aluminium Nitride (AlN) is chosen as the material of the coil bobbin, since it features much higher thermal conductivity $\left(\kappa_{A l N}=180 \mathrm{~W} / \mathrm{mK}\right)$ compared to other industrial ceramics. In fact, thermal conductivity of ceramics will decay substantially after neutron irradiation. Nevertheless, with the expected neutron fluence over ITER lifetime $\left(2.5 \sim 5.0 \times 10^{24} / \mathrm{m}^{2}\right), \kappa_{A l N}$ will decrease to about $30 \mathrm{~W} / \mathrm{mK}$ ([7]), which is still reasonably good. (For information, this is approximately the thermal conductivity for non-irradiated $\mathrm{Al}_{2} \mathrm{O}_{3}$ with $99.8 \%$ purity). Changes in geometric (dimensional), mechanical, and electrical properties for AlN are negligibly small at the expected irradiation dose ([8]).

Coil design specifications are given in Table 2. Key electrical parameters of the coil were calculated using these data with results summarized in Table 2 . This coil exhibits both low inductance $(42 \mu \mathrm{H})$ and low DC resistance $\left(0.8 \Omega\right.$ at $20^{\circ} \mathrm{C} ; 1.12 \Omega @ 120^{\circ} \mathrm{C}$, ITER operating temperature).

The concept of using LTCC (Low-Temperature Co-fired Ceramic) sensors for HF magnetic measurement in ITER has also been studied. Within the available space, the largest LTCC coil that could meet the design target of $A_{\text {eff }} \geq 0.05 \mathrm{~m}^{2}$ has higher inductance of $90 \mu \mathrm{H}$ and resistance of $40 \Omega$ (ref. Table A4). Yet, in real application with loading network connected (transmission lines and termination load, ref. Table 5), the high impedance of LTCC sensor lead to unfavorable frequencydomain response, especially at high frequencies above $100 \mathrm{kHz}$. More details are discussed in Appendix 4. For this reason LTCC sensor is not opted for ITER HF pickup coil.

\subsection{ECH shield}

The expected load on ITER in-vessel components arising from ECH power was studied and reported in [9]. During normal operation, the vessel-averaged stray ECH power density is expected to be 15$20 \mathrm{~kW} / \mathrm{m}^{2}$. However, in ITER plasma startup phase, the stray ECH power density may locally reach $3 \mathrm{MW} / \mathrm{m}^{2}$, which is foreseen to be the highest during ITER operation, and last for about 5.5 seconds. Unfortunately, ceramic is known to be a good radiation absorber at ITER ECH frequency of $170 \mathrm{GHz}$ (e.g., $80 \%$ absorption for $\mathrm{Al}_{2} \mathrm{O}_{3}-\mathrm{TiO}_{2} 87 \%-13 \%$ ceramic according to [15]). If the pickup coil is exposed to direct ECH power without proper shielding, such exposure could substantially heat the coil over a short period of time, leading to thermal stresses that may crack or even break the coil. The $\mathrm{ECH}$ shield is therefore an indispensable component for coil protection. 
Design of ECH shield for the HF sensor must simultaneously meet the following requirements:

1. The shield should effectively reject ECH waves with characteristic frequency of $170 \mathrm{GHz}$;

2. The shield should not excessively attenuate magnetic perturbations with frequencies below $500 \mathrm{kHz}$;

3. The shield should not substantially alter the frequency response of the system;

4. The shield (and the coil to some extent) must meet environmental requirements, including offnormal events such as exposure to hot hydrogen and steam.

Candidate shield design options include: 1) a thin metal enclosure; 2) a thin metal enclosure with slit openings; 3) a ceramic enclosure coated with thin metal film. Unfortunately, the first two options were found unable to simultaneously meet all design requirements. The first option fails as it attenuates excessively the magnetic perturbations below $500 \mathrm{kHz}$. To demonstrate this, consider for geometric simplicity, a $5 \mathrm{~cm}$ long stainless steel $\left(\sigma=1.45 \times 10^{6} \mathrm{~S} / \mathrm{m}\right.$ at $\left.20^{\circ} \mathrm{C}\right)$ cylindrical tube with $3 \mathrm{~cm}$ inner radius $(R)$ and $1 \mathrm{~mm}$ wall thickness $(\Delta)$, that is large enough to enclose the coil (see Figure 3 ). The magnetic attenuation factor, $f_{s}$, is defined as the ratio of magnetic field inside the shield $\left(B_{i}\right)$ to the externally applied field $B_{e}$ ([10], pp.23-70):

$$
f_{s} \equiv \frac{B_{i}}{B_{e}}=\frac{1}{\cosh (\gamma \Delta)+0.5 \gamma(R+\Delta) \sinh (\gamma \Delta)}
$$

with $\gamma=(1+j) / \delta$ for good conductor, $\delta=1 / \sqrt{\pi f \mu \sigma}$ the skin depth. Figure 3 reveals that $\left|f_{s}\right| \sim 0.7$ (i.e., $3 \mathrm{db}$ attenuation) at $\sim 10 \mathrm{kHz}$, falling sharply to $\left|f_{s}\right|<1 \%$ at $500 \mathrm{kHz}$. The metal thickness has to be reduced to a few micrometers in order for the attenuation to become minor at $500 \mathrm{kHz}$. Apparently, metal structure is not self-supported at this thickness.
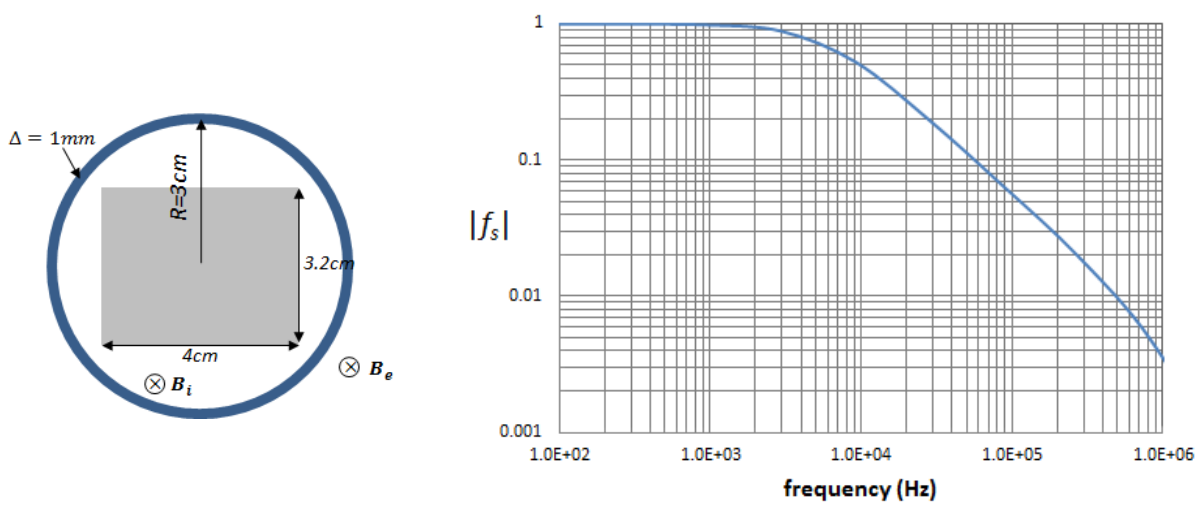

Figure 3 : magnetic attenuation generated by a $1 \mathrm{~mm}$ thick, $R=3 \mathrm{~cm}$ stainless steel cylindrical tube.

Cutting slits could truncate the eddy currents flowing on the shield surface therefore reduce the shielding. However, slit openings also invite direct ECH leakage into the shield. For instance, a $1 \mathrm{~mm}$ wide continuous slit, cut on the side surface and the end plates of the aforementioned cylindrical structure (see Figure 3, the slit is thus $6+5+6=17 \mathrm{~cm}$ long), could incur $500 \mathrm{~W}$ direct ECH power leakage into the shield in the worst case with $p_{E C H}=3 \mathrm{MW} / \mathrm{m}^{2}$. Besides, to effectively avoid magnetic attenuation at $\sim 100 \mathrm{kHz}$, the end plates of this shield need to be removed, so that magnetic flux can enter without much resistance. Yet, this large opening will introduce enormous (about $15 \mathrm{~kW}$ ) heating to the coil. Therefore, the second option also seems impractical.

Based on these facts, ceramic enclosure with thin metal coating is the adopted concept for the ECH shield design. Figure 4 illustrates the physical principle. When $170 \mathrm{GHz}$ ECH waves hit the metal coating, most get reflected due to the large mismatch of wave impedance in the two media, and only a small fraction of the incident wave can enter the coating. Power of the waves transmitted into the 
coating decay exponentially during propagation due to the eddy current dissipation, characterized by $P(z) \sim e^{-2 z / \delta_{s}}\left(\delta_{s}\right.$ is the skin depth in metal, and $z$ the distance from the surface of the coating). If the coating is electrically thick, meaning that $d>4 \sim 5 \delta_{s}$ ( $d$ is the thickness of the coating), the transmitted waves will experience strong damping in the coating layer, and only some tiny residuals can reach the ceramic substrate behind it.

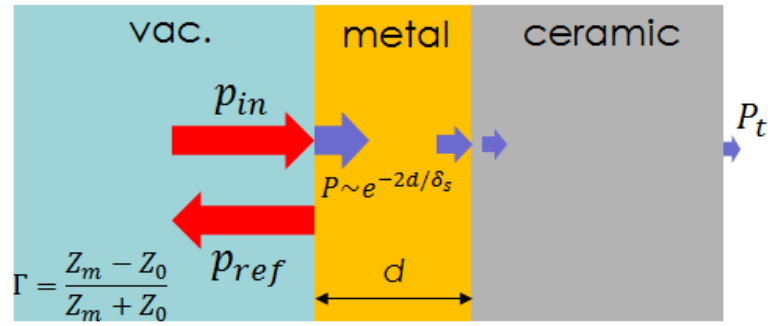

Figure 4: illustration of the physical principle for a metal coated ceramic shield.

The ECH shield designed based on this principle is shown in Figure 5. The shield is made of AlN ceramic. The outer surfaces and base rim are coated with titanium. The thickness of the titanium coating is chosen to be $4 \mu m$, i.e. approximately five skin depths at $170 \mathrm{GHz}$. The main reason for selecting titanium as the coating material is that it can be relatively easily deposited on AlN with strong adhesion at the prescribed thickness, according to practical experience, and that titanium is non-magnetic. Calculation using a simple 1D infinite-slab analytical model ([10] pp.21-41, formula also given in Table 3 ) indicates that the shield of this particular design can produce $80 \mathrm{db}$ power attenuation at $170 \mathrm{GHz}$. A numerical simulation using a high-frequency electromagnetic (EM) solver was performed on a $3 \mathrm{~mm}$ thick, $4 \mathrm{~mm}$ diameter AlN disk with $4 \mu \mathrm{m}$ titanium coating. The simulation yields $\sim 70 \mathrm{db}$ attenuation, which is in general agreement with the 1D analytical model prediction.
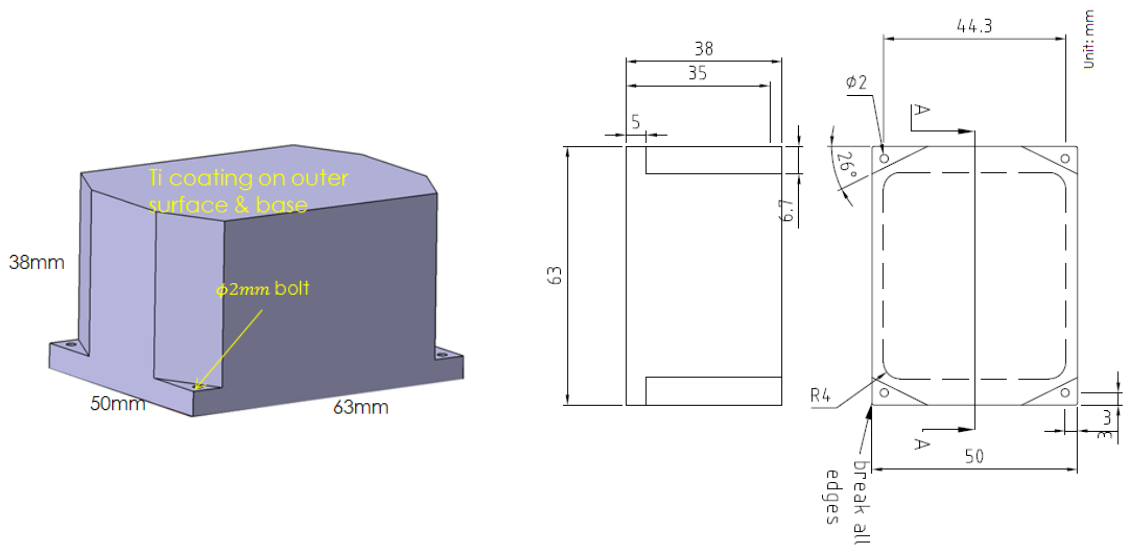

Figure 5 : ECH shield design with (left) 3D model; and (right) technical drawing (courtesy of CCFE).

\begin{tabular}{|c|c|c|}
\hline \multicolumn{2}{|c|}{ Substrate } & \multirow{5}{*}{$\begin{array}{c}\delta_{s}=1 / \sqrt{\pi f \mu \sigma} \\
Z_{m}=(1+j) \rho_{u} / \delta \\
\text { Atten }_{d h}=10 \log _{10}(\text { power ratio }\end{array}$} \\
\hline Material & AlN & \\
\hline dielectric constant & $\epsilon_{r} \approx 9.0$ & \\
\hline dielectric loss & $\zeta \approx 0.95$ & \\
\hline \multicolumn{2}{|c|}{ Coating } & \\
\hline Material & Titanium & \multirow{6}{*}{$\approx \frac{8.69 d}{\delta_{s}}+20 \log _{10}\left|\frac{377}{4 Z_{m}}\right|^{1}$} \\
\hline Thickness & $d=4 \mu m$ & \\
\hline resistivity $\left(20^{\circ} \mathrm{C}\right)$ & $\rho_{u}=4.2 \times 10^{-7} \Omega \mathrm{m}$ & \\
\hline skin depth (170GHz) & $\delta_{s}=0.8 \mu \mathrm{m}$ & \\
\hline impedance (170GHz) & $Z_{m} \approx 0.5(1+j) \Omega$ & \\
\hline power attenuation $(\mathrm{db})$ & Atten $_{d b} \approx 80$ & \\
\hline
\end{tabular}

Table 3: properties for the metal coated ceramic shield as illustrated in Figure 5. 
To assess the performance of the shield below $500 \mathrm{kHz}$, the structure is geometrically approximated by a $5 \mathrm{~cm}$ outer diameter, $6 \mathrm{~cm}$ long ceramic cylinder coated with $4 \mu \mathrm{m}$ thick titanium. Given that the thickness of coating is significantly smaller than the skin depths in this frequency range $\left(\delta_{s}>\sim 500 \mu \mathrm{m}\right)$, one obtains $f_{s} \approx 1 /\left(1+j \omega a \mu_{0} \sigma \Delta / 2\right)$ ([10], pp.23-65), with $a=2.5 \mathrm{~cm}$ and $\Delta=4 \mu \mathrm{m}$. Figure 6 plots $f_{s}$ for various frequencies. It suggests that the shield barely attenuates magnetic field below $500 \mathrm{kHz}$. The presence of a shield reduces the inductance of the enclosed coil as the two objects are magnetically coupled. This phenomenon can be studied using the transformer model, assuming strong magnetic coupling with the coupling coefficient $k \approx 1$. The actual (effective) coil inductance is ([10], pp.22-16): $L_{e f f}=L_{c} /\left(1+\omega^{2} \tau_{s}^{2}\right)$, with $\tau_{s}=\mu_{0} a \sigma \Delta / 2$ the characteristic $(L / R)$ time of the shield. Coil inductance decrease from $42 \mu \mathrm{H}$ in DC to about $35 \mu \mathrm{H}$ at $500 \mathrm{kHz}$, as shown in Figure 6. In principle, this design should satisfy the design requirements put forward at the beginning of this section. Prototypes of the shield were put on lab testing to experimentally validate the design (see Chapter 5).
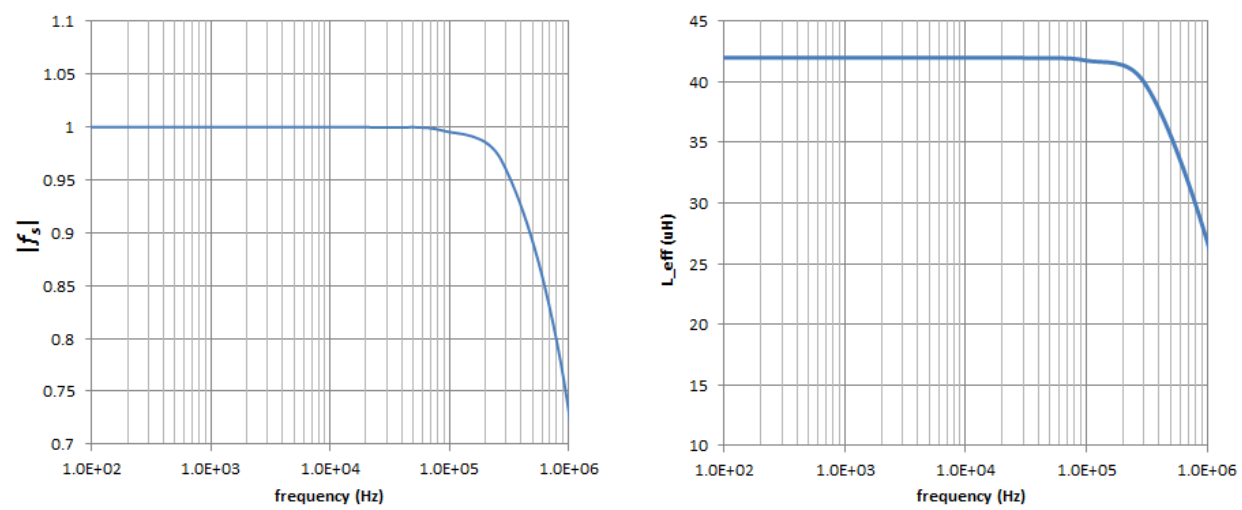

Figure 6 : (left) attenuation; (right) influence on coil inductance generated by a $5 \mathrm{~cm}$ outer diameter, $6 \mathrm{~cm}$ long ceramic cylinder canister coated with $4 \mu m$ thick titanium.

\subsection{Electric Cabling}

The electrical cabling comprises the in-vessel (inside VV) section and ex-vessel (outside VV) section. The in-vessel cabling will operate in a harsh environment with high vacuum and high neutron/nuclear irradiation level. Therefore, the heavy-duty mineral insulated cable (MIC), which has broad application in nuclear industries, is selected. In particular, the two-core twisted-pair (i.e. the two conductors are braided for electromagnetic interference reduction) design is adopted for this purpose. Cross section of the cable is shown in Figure 7. Impedance $\left(Z_{0}\right)$, capacitance $\left(C_{0}\right)$, and inductance $\left(L_{0}\right)$ of this cable are calculated for two different insulation materials: alumina $\left(\mathrm{Al}_{2} \mathrm{O}_{3}\right)$, and silica $\left(\mathrm{SiO}_{2}\right)$. Results are summarized in Table 4. Silica insulated cable has lower capacitance and higher impedance, making it a favorable choice for HF applications.

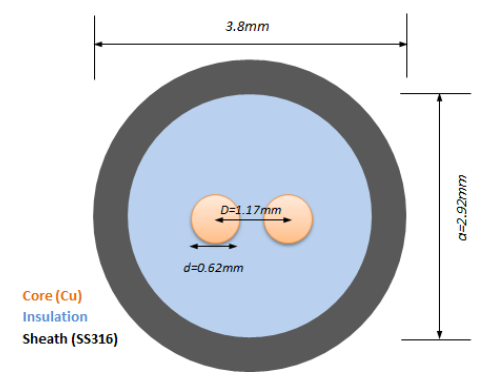

Figure 7: cross section for the two-core twisted MIC.

\begin{tabular}{|c|c|c|c|c|}
\hline $\begin{array}{c}\text { MIC } \\
\text { Insulation }\end{array}$ & $\epsilon_{r}$ & $C_{0}[p F / m]$ & $L_{0}[\mu H / m]$ & $Z_{0}[\Omega]$ \\
\hline $\mathrm{Al}_{2} \mathrm{O}_{3}$ & $\begin{array}{l}9.8 \\
\end{array}$ & 280 & 0.4 & 40 \\
\hline $\mathrm{SiO}_{2}$ & 3.9 & 110 & 0.4 & 65 \\
\hline $\begin{array}{r}p=D / d=1.88 \\
q=D / a=0.4\end{array}$ & \multicolumn{4}{|c|}{$\begin{array}{c}Z_{0}=\frac{1}{\pi}\left(\frac{\mu_{0} \mu_{r}}{\epsilon_{0} \epsilon_{r}}\right)^{\frac{1}{2}}\left[\ln \left(2 p \frac{1-q^{2}}{1+q^{2}}\right)-\frac{1+4 p^{2}}{16 p^{4}}\left(1-4 q^{2}\right)\right] \\
\quad C_{0}=\left(\mu_{0} \epsilon_{0} \epsilon_{r}\right)^{1 / 2} / Z_{0}, \quad L_{0}=\left(\mu_{0} \epsilon_{0} \epsilon_{r}\right)^{1 / 2} Z_{0}\end{array}$} \\
\hline
\end{tabular}

Table 4: electrical parameters for alumina and silica MIC with sectional layout as shown in Figure 7 
Radiation level falls sharply outside the ITER VV. Therefore, standard data cables can be considered as options for the ex-vessel cabling. Because of the long length (about $150 \mathrm{~m}$ is foreseen), lowcapacitance cable is preferred in order to minimize the impact of ex-vessel cabling on frequency response. One potential choice is the RS- 485 data cable with $C_{0}=42 \mathrm{pF} / \mathrm{m}$ and $Z_{0}=120 \Omega$. Even lower capacitance can be achieved using larger diameter cables with foam or partial air insulation.

\section{System Performance Assessment}

\subsection{Global frequency response}

The HF sensor system can be represented by the electrical diagram in Figure 8. In this diagram, the pickup coil is modelled by an RLC circuit. Two segments of transmission line connected in series represent the in-vessel and the ex-vessel cabling, respectively. The ex-vessel line is terminated at the output end by a resistive load $\left(R_{L}\right)$, across which the output voltage $\left(V_{L}\right)$ is measured. Electric cabling (transmission lines) and the termination load together form the loading network.

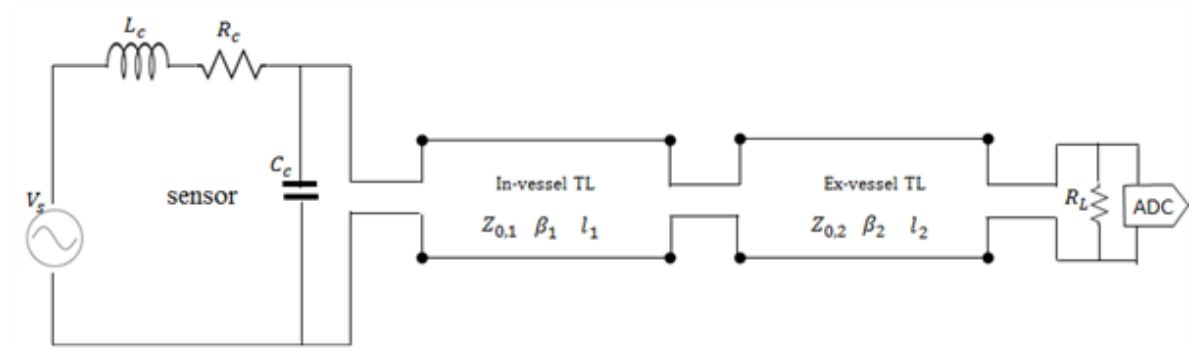

Figure 8 : electrical diagram of the HF sensor system.

The transmission line model ([10], chapter 13.33) is applied to reduce this complex loading network into a simple lumped-element circuit for frequency response analysis. Input parameters and their values are summarized in Table 5. Two termination scenarios were studied: 1 ) $R_{L}=Z_{0,2}=120 \Omega$ (i.e., termination load matches the ex-vessel line impedance); 2) $R_{L}=1 \mathrm{G} \Omega$ (open termination).

\begin{tabular}{|c|c|c|}
\hline Element & Type/Design & Paramaters $/$ Values \\
\hline Pickup Coil & Section 2.1 & $R_{c}=0.8 \Omega, L_{c}=42 \mu \mathrm{H}, C_{c}=40 p F$ \\
\hline \multirow{2}{*}{ In-vessel line } & $\mathrm{SiO}_{2} \mathrm{MIC}$, & $Z_{0}=65 \Omega, C_{0}=110 p F / m, \epsilon_{r}=4.0$, \\
& Section 2.3 & $v_{p h}=1.5 \times 10^{8} \mathrm{~m} / \mathrm{s}, l=20 \mathrm{~m}$ \\
\hline \multirow{2}{*}{ Ex-vessel line } & $\begin{array}{c}\mathrm{RS}-485 \text { cable, } \\
\text { Section } 2.3\end{array}$ & $\begin{array}{c}Z_{0}=120 \Omega, C_{0}=42 p F / m, \epsilon_{r}=2.25, \\
v_{p h}=2 \times 10^{8} \mathrm{~m} / \mathrm{s}, l=150 \mathrm{~m}\end{array}$ \\
\hline Load & Resistive & $R_{L}=120 \Omega$, or $R_{L}=1 G \Omega$ \\
\hline
\end{tabular}

Table 5: input parameters and values for the HF sensor frequency response analysis.

Sensitivity of output voltage $V_{L}$ to the applied time-varying (sinusoidal) magnetic field is defined as $S E=20 \log _{10}\left(V_{L} / B\right)$. Figure 9 shows that with matched load the frequency response of $S E$ is linear in $\log _{10} f$ (with an offset) without resonances. While two clear resonances below $1.0 \mathrm{MHz}$ are identified with open termination. The first one at $\sim 200 \mathrm{kHz}$ corresponds to the resonance between the two 
transmission lines. The second one at $\sim 600 \mathrm{kHz}$ arises when the length of the ex-vessel line equates half the wavelength therefore a phase shift of $\pi$ is generated.

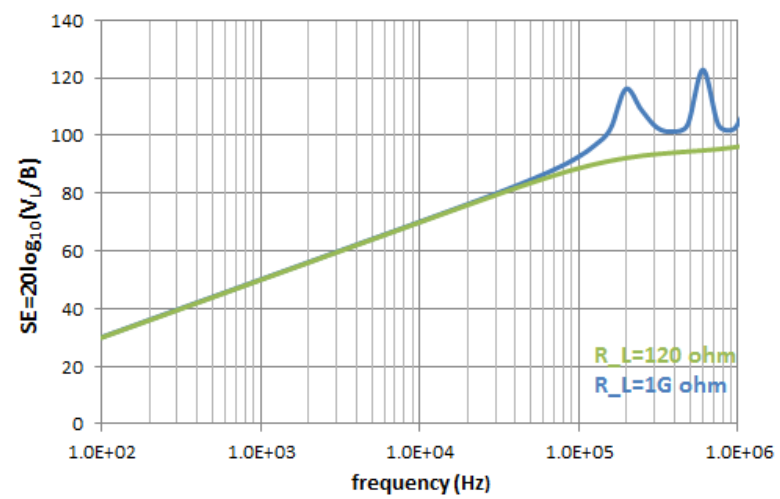

Figure 9: output sensitivity of the HF sensor system for open $\left(R_{L}=1 G\right.$ ohm $)$ and matched $\left(R_{L}=120\right.$ ohm $)$ termination, simulated using the data in Table 5 .

For a given termination scheme, the study also reveals that $S E$ is sensitive to the electrical properties $\left(C_{0}, Z_{0}\right)$ of ex-vessel cabling. For instance, using RH-232 cable $(40 \mathrm{pF} / \mathrm{m}, 100 \Omega)$ instead of RH-485 cable as ex-vessel transmission line will downshift the resonances by about $50 \mathrm{kHz}$. While compared to silica MIC $(110 \mathrm{pF} / \mathrm{m}, 65 \Omega)$, using alumina MIC $(280 \mathrm{pF} / \mathrm{m}, 40 \Omega)$ as in-vessel line slightly downshifts the first resonance, but reduces the second resonance frequency by $150 \mathrm{kHz}$. These results confirm that low-capacitance cables are favourable for high frequency performance.

\subsection{Thermal conductance}

Coil and shield are mechanically fastened on a metal plate (which represents the platform to which they are mounted) using bolt joints. The heat transfer process from the coil (also the shield) to the underlying plate comprises: 1) heat conduction inside the coil body, and 2) interfacial contact heat conductance at joining surface. The heat flow pattern is illustrated in Figure 10. The interfacial contact conductance occurs only in the vicinity of the bolt, where compressional force is present.
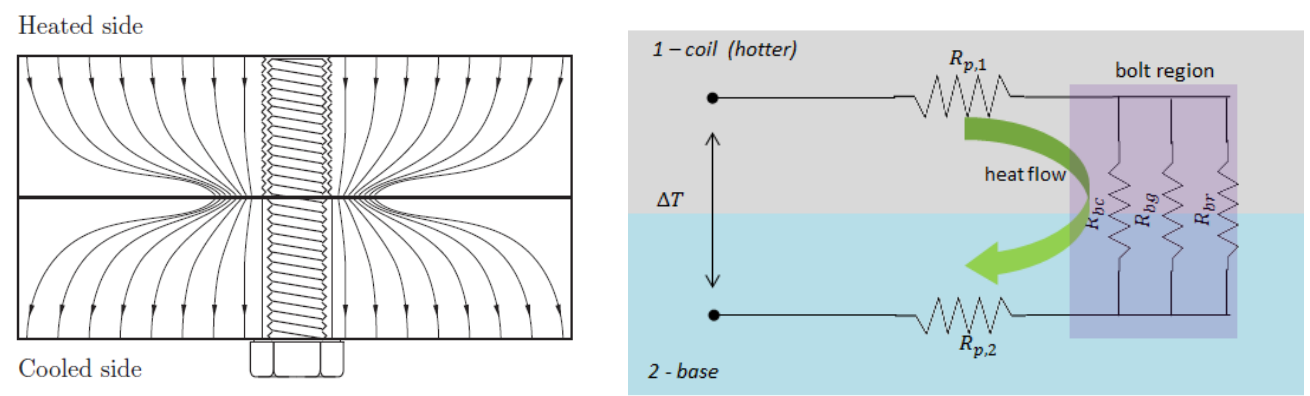

Figure 10: (left) an illustration of heat flow within bolted objects; (right) equivalent thermal circuit utilized to model the heat transfer process shown on the left.

The heat transfer process can be modelled using the equivalent thermal circuit shown in Figure 10. The overall thermal resistance is $R_{s}=R_{b}+R_{c}$. The term $R_{b}=R_{b, 1}+R_{b, 2}$ represents the total body thermal resistance. It is modelled approximately using the Bevans equation ([12]) for two circular plates of 
radius $R$, thermal conductivity $\left\{\kappa_{1}, \kappa_{2}\right\}$, and thickness $\left\{t_{1}, t_{2}\right\}$, and fastened together by a bolt with head radius $R_{0}$ as: $R_{b} \approx\left[\eta_{0}^{2}-0.25 \eta_{0}^{4}-\ln \left(\eta_{0}\right)-0.75\right] / 2 \pi \kappa t$, with $1 / \kappa t=1 / \kappa_{1} t_{1}+1 / \kappa_{2} t_{2}$, and $\eta_{0}=R_{0} / R$.

Contact thermal resistance, $R_{c}$, is evaluated using the CMY (Copper-Mike-Yovanovich) model ([13]):

$$
R_{c} \approx 0.01 \sqrt{\sigma_{s}} H_{m i c} / \kappa_{s} F
$$

$\kappa_{s}=2 \kappa_{1} \kappa_{2} /\left(\kappa_{1}+\kappa_{2}\right):$ effective thermal conductivity

$\sigma_{s}=\sqrt{\sigma_{1}^{2}+\sigma_{2}^{2}}$ : r.m.s. surface roughness for the two objects in contact

$F$ : the compressional (bolting) force

$H_{m i c}$ : microhardness for the softer of the two materials in contact, related to the bulk hardness by the empirical scaling law eqn.(12) of [14] (this scaling is applicable to most metal-metal and metalceramics joint with bulk hardness of the softer material less than 2.2GPa) .

The model presented above is applied to estimate the thermal resistance for the coil-plate assembly. The assessment was done for three candidate coil materials: AlN, Shapal-M (a soft machinable AlN ceramic), and alumina $\left(\mathrm{Al}_{2} \mathrm{O}_{3}\right)$, in junction with three candidate materials for the mounting plate: Glidcop® diffusion strengthened (DS) copper, copper-beryllium $(\mathrm{CuBe})$, and Grade 316L stainless steel (SS). Bulk hardness and thermal conductivity for these materials are listed in Table 6 . Surface roughness largely depends on surface finish. Typically, $\sigma \sim 10 \mu m$ is expected for milled metal and ceramics. Therefore, it is reasonable to assume $\sigma_{s}=30 \mu \mathrm{m}$, also taking into account possible imperfections on the interface (e.g. indentations). Take a standard ISO898/1- C3.6 M4 bolt, which generates approximately $F=1300 \mathrm{~N}$ compressional load. Overall thermal resistance for various material combinations against the thickness of the mounting plate are shown in Figure 11. Apparently, AlN coil with Glidcop copper plate gives the smallest $R_{s}$, since both materials have the highest thermal conductivity. $R_{s}$ is also found to generally decrease with the thickness of the mounting plate, most prominent in the case of thin plate with thickness less than $2 \mathrm{~mm}$.

\begin{tabular}{|c|c|c|c|}
\hline coil material & AlN & Shapal-M & $\mathrm{Al}_{2} \mathrm{O}_{3}$ \\
\hline$H_{\text {mic }}(G P a)$ & 10.0 & 4.0 & 13 \\
\hline$\kappa(W / m K)$ & 180 & 90 & 40 \\
\hline \multicolumn{4}{|c|}{} \\
\hline plate material & Glidcop & Cu-Be & $316 \mathrm{~L} \mathrm{SS}$ \\
\hline$H_{\text {mic }}(\mathrm{GPa})$ & 1.2 & 1.2 & 1.4 \\
\hline$\kappa(\mathrm{W} / \mathrm{mK})$ & 350 & 130 & 16.3 \\
\hline
\end{tabular}

Table 6: hardness and thermal conductivity data for concerned coil and plate materials.

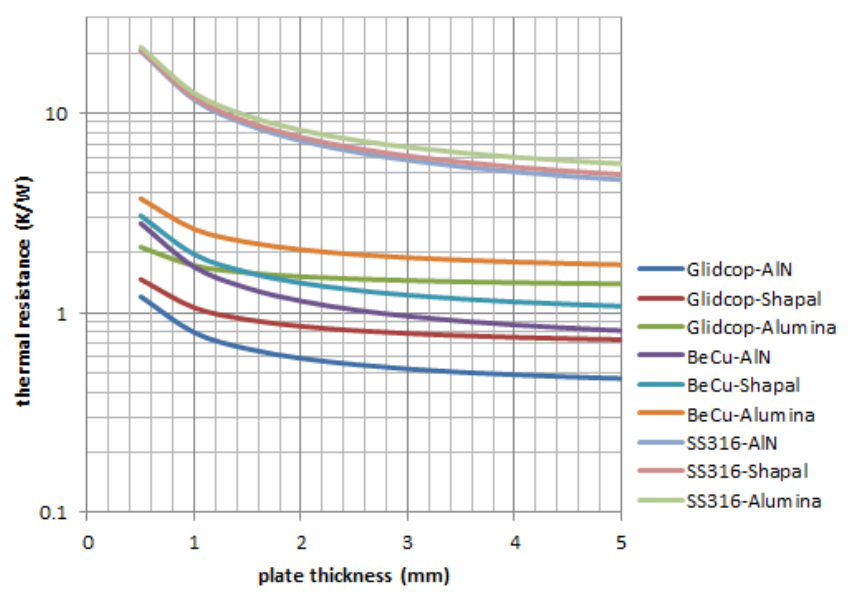

Figure 11: thermal resistance for various coil-plate material combinations with $F=1300 N$. 


\section{Prototyping}

A prototyping campaign was initiated to demonstrate the manufacturability of the components. These prototypes have also been put on lab testing to experimentally validate the design (Chapter 5).
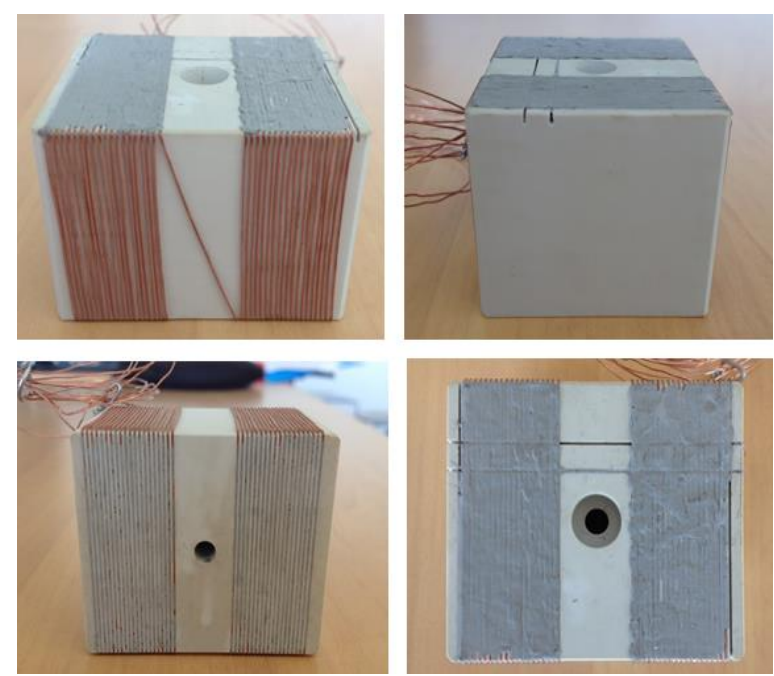

Figure 12: a prototype for the pickup coil

Prototypes of the pickup coil and the ECH shield were produced at CCFE. In total, 3 prototypes of pickup coil and 5 prototypes of ECH shield have been successfully manufactured. Shown in Figure 12 is a manufactured pickup coil prototype. To produce this item, a Shapal-M® (soft machinable AlN ceramic, ref. Table 6 , chosen because it is easier to machine thus suitable for the fast prototyping purpose) block was first machined into a coil bobbin according to the design specifications. A copper wire was then tightly wound around the bobbin into the grooves on the top and bottom surface. After winding, Ceramabond ${ }^{\circledR} 865$ ceramic adhesive was syringed into the grooves to bond the copper wire with the bobbin. Only proper amount was applied with excessive adhesive carefully removed. Finally, the coil was cured in air and vacuum for several times till the bonding was firmly cemented.

Figure 13 shows a prototype of the ECH shield. The structure was machined from a Shapal-M block. It was thoroughly cleaned to remove any remnant dirt/contaminants on the surface before coating. Coating was done in vacuum using the physical vapor deposition (PVD) technique. Outer surfaces and the base of the ceramic structure were coated with grade- 2 titanium. The supplier estimated (based on the influx and deposition rates) that the coating could be about $6 \mu \mathrm{m}$ thick on the top surface, and about 3.6 $\mu \mathrm{m}$ thick on side surfaces. The variation is within $30 \%$ of the target value of $5 \mu \mathrm{m}$.
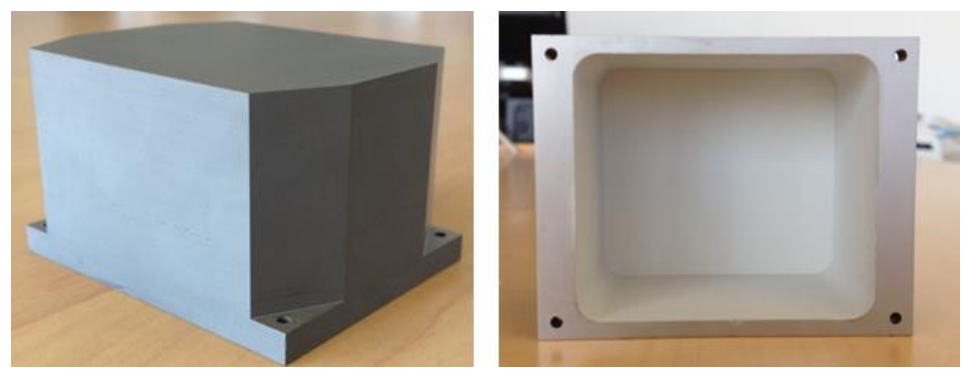

Figure 13: a prototype of the ECH shield. 
Prototypes of silica insulated MIC as designed and a simple stainless steel baseplate (utilized to mount coil and ECH shield in the microwave radiation test, see Section 5.3) were also manufactured, shown in Figure 14. The top surface of the baseplate is sprayed with $0.3 \mathrm{~mm}$ thick copper to enhance heat conduction.
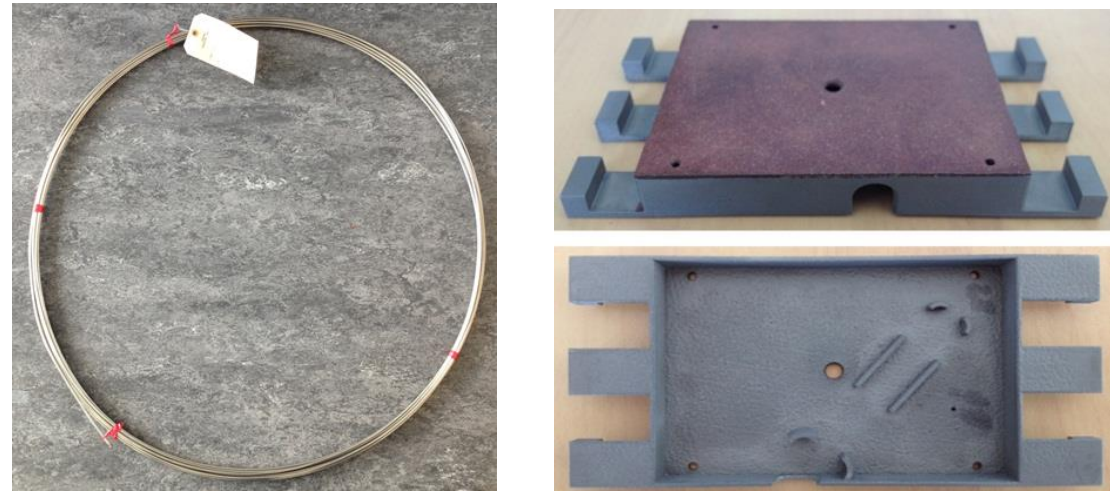

Figure 14: (left) a 20m spool silica insulated MIC; (right) a stainless steel baseplate utilized to mount coil and ECH shield in the stray radiation test (Section 5.3).

\section{Lab Testing and Inspection}

The produced prototypes have been dispatched to various research institutes for measurement of key properties in order to validate the design. An overall summary of these can be found in Appendix 1 .

\subsection{Assembly and thermal test}

Assembly and thermal tests were conducted at CCFE following the production of prototypes. The assembly test aimed to seek and demonstrate a proper way to fasten the coil and the $\mathrm{ECH}$ shield to a metal plate (to mock up the platform). A 3mm thick Glidcop® ${ }^{\circledR} \mathrm{Al}-15$ copper plate was used in the test to simulate the support platform. The coil was fastened to the Glidcop ${ }^{\circledR}$ plate using a M4 bolt. Four Belleville spring washers were stacked up and put underneath the plate. They were measured to retain about $1000 \mathrm{~N}$ compressional load when the bolt was tightened. The shield was fastened to the plate in a similar way using four M2 sized bolts. Two spring washers were inserted for each bolt joint. Closeup pictures of the joints are shown in Figure 15 (these pictures were taken during the test). Three sets of assembly have been successfully built.

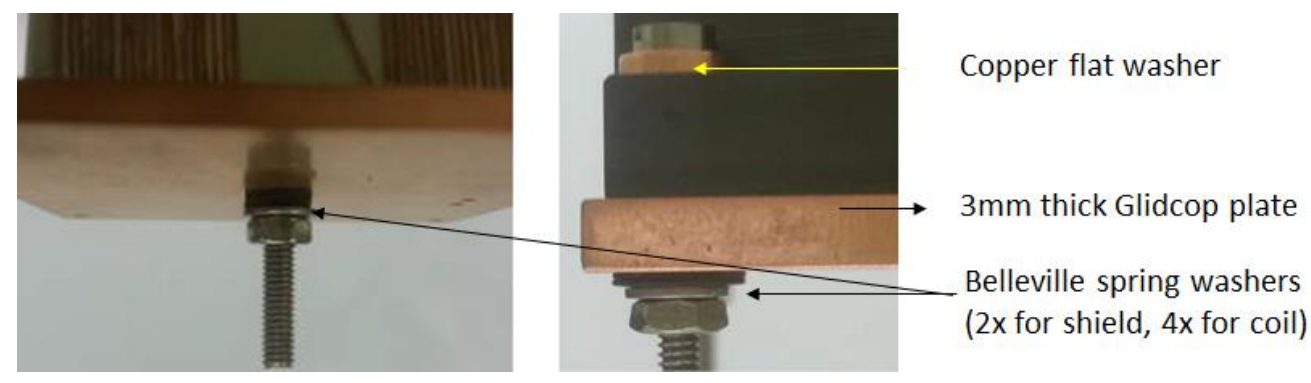

Figure 15: close-up view of the bolt joints (taken in lab during the assembly test).

These assemblies were placed in an oven for thermal cycling test to examine the integrity of the mechanical joints under thermal stress. The oven temperature was first increased from approximately $20^{\circ} \mathrm{C}$ (room temperature) to $220^{\circ} \mathrm{C}$ (baking temperature of ITER VV) at a linear ramp-up rate of $300^{\circ} \mathrm{C}$ 
per hour (ITER VV baking rate is $50^{\circ} \mathrm{C}$ per hour), then naturally cooled down to room temperature to conclude a full thermal cycle. In total 10 thermal cycles were achieved. The joints were inspected after the test and found to remain tight. No crack or damage was discovered on ceramic surface.

Heat transfer between components was measured. Three thermocouples were deployed to record the temperature of coil bobbin, shield, and Glidcop ${ }^{\circledR}$ plate, respectively. Locations of these thermocouples are as shown in Figure 16. Tails of the coil winding were sleeved with ceramic tubes for electric insulation. The components were fastened in the same manner as in the assembly test. The assembly was meticulously placed inside a vacuum chamber after installation. The chamber was pumped down to about $0.01 \mathrm{~Pa}$. At this pressure, air-gap heat conduction is negligible and conduction is the sole dominant heat transfer mechanism. Steady DC electric current of $1.0 \mathrm{~A} \pm 50 \mathrm{~mA}$ generated by a Rigol DP832 power supply was driven into the coil through the tails of the winding and heated up the coil. Data recorded by the thermocouples are plotted in Figure 16. Temperature differences between different components were noticed to become steady near the end of the test. Thermal resistance between the coil and the mounting plate was calculated from: $R_{S}=\Delta T / P_{\text {input }}$. With $\Delta T \approx 1.0 \mathrm{~K}$ and $P_{\text {input }} \approx 1.2 \mathrm{~W}$ measured in the experiment, we get $R_{S} \approx 0.83 \mathrm{~K} / \mathrm{W}$, which is close to the theoretical prediction of $R_{s} \sim 0.8 \mathrm{~K} / \mathrm{W}$ (see Figure 11, for shapal-glidcop joint with $F=1300 \mathrm{~N}$ ).
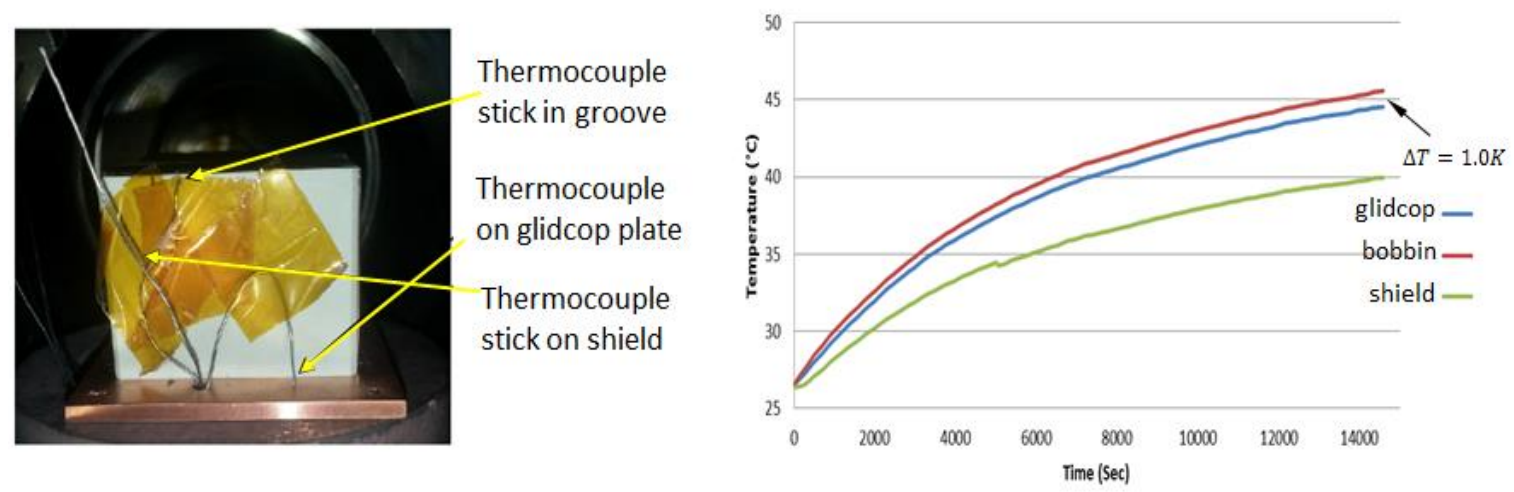

Figure 16: (left) arrangement of thermocouples for the thermal conductance test; (right) thermocouples measurement in the thermal conductance test with 1.0A DC current driven into the coil.

\subsection{Electrical test}

A series of electrical tests were performed in the electronics lab at CEA to measure the key parameters of the HF sensor and the frequency response in different loading network configurations. A type MT4049 impedance meter was utilized to measure the impedance of the pickup coil. A densely packed slender solenoid was employed to generate time-varying magnetic field at various frequencies to enable frequency domain measurements. The solenoid is $0.69 \mathrm{~m}$ long with 180 winding turns. Winding turn diameter is $110 \mathrm{~mm}$. A Philippe PM5193 generator was utilized to drive electric current into the solenoid. Magnetic field $(B)$ created inside the solenoid was in the axial direction and is linked with the driving current (I) by $B=\mu_{0} N I / l$, with $N=180$, and $l=0.69 \mathrm{~m}$. The pickup coil was placed inside the solenoid cylinder with its axis positioned to align with the magnetic field. A Lecroy 9350A oscilloscope was employed to monitor the input electric currents to the solenoid, as well as to measure the output voltage of the coil system. The oscilloscope was set up to operate in the default AC mode with the input impedance of $R_{o s c}=1 \mathrm{M} \Omega, C_{o s c}=15 \mathrm{pF}$. These are illustrated in Figure A2. 
Measurement results of key electrical parameter of the coil are found very close to the calculate values, as shown in Table 7. An independent RLC measurement at TU/e for a different coil prototype yielded similar results. Details about these measurements can be found in Appendix 2.

\begin{tabular}{|c|c|c|}
\hline Parameter & Calculation (from Table 2) & Measured Value \\
\hline$R_{c}(\Omega)$ & 0.8 & 0.788 \\
\hline$L_{c}(\mu H)$ & 42 & 42.4 \\
\hline$C_{c}(p F)$ & 40 & $44.5 \neq$ \\
\hline$A_{\text {eff }}\left(m^{2}\right)$ & 0.048 & $0.048 \pm 5 \% \dagger$ \\
\hline $\begin{array}{l}\text { ₹ inferred from } f_{\text {res }}=1 / 2 \pi \sqrt{L C}=1 / 2 \pi \sqrt{L_{c}\left(C_{c}+C_{\text {osc }}\right)} \text { with } f_{\text {res }}=3.3 \mathrm{MHz} \text { the self- } \\
\text { resonance frequency of the coil measured in the absence of loading network. } \\
\dagger \text { maintained up to 500kHz. }\end{array}$ \\
\hline
\end{tabular}

Table 7: measurement results of key electrical parameters of the pickup coil in comparison with calculation.

To simulate the real arrangement, the pickup coil was connected in series with a $20.7 \mathrm{~m}$ long silica insulated MIC manufactured according to the design specifications (Figure 7), followed by a segment of $150 \mathrm{~m}$ long $50 \Omega$ data cable (simulate the ex-vessel line) terminated by a resistive load. The ECH shield was not covered in this measurement. Impedance of the silica MIC measured $72 \Omega$, close to the calculation $(65 \Omega$, see Table 4$)$. Output end of the data cable was terminated either by a $50 \Omega$ resistor or left open, corresponding to the matched and open termination, respectively. The parameter employed to characterize the sensor's response to externally applied magnetic field is again the decibel sensitivity $S E=20 \log _{10}\left(V_{L} / B\right)$, with $V_{L}$ the output voltage and $B$ the applied magnetic field. Frequency response of $S E$ derived from experimental data and simulated using the transmission line model are plotted in Figure 17, for both matched and open termination configurations. It is seen that experimental results are in good agreement with simulation.

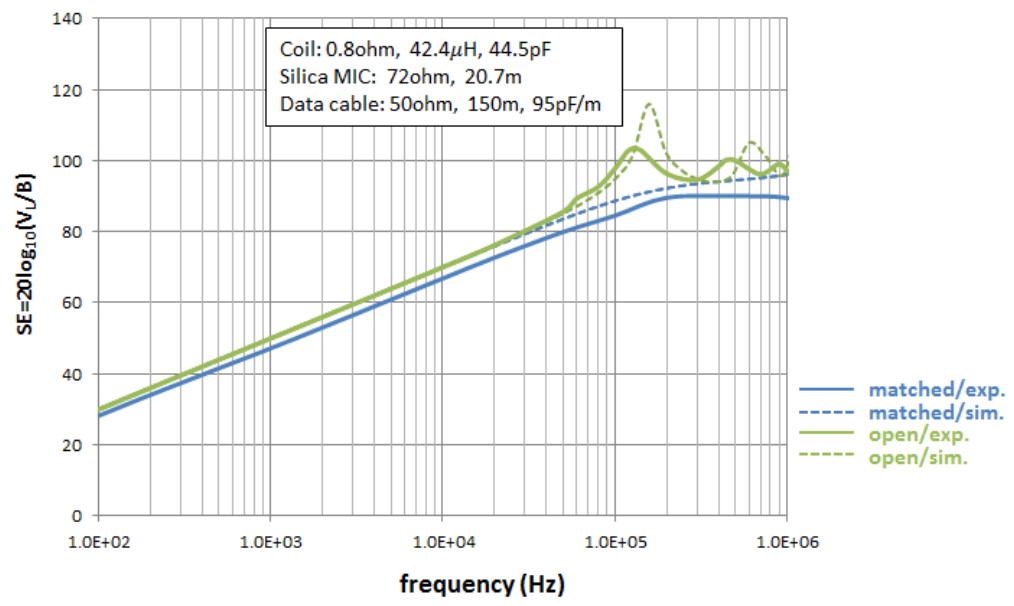

Figure 17: measured (solid lines) and simulated (dashed lines) HF sensor system frequency response in matched and open termination configurations.

Influence of the shield was examined by measuring the frequency response of a bare pickup coil and comparing to that of a pickup coil fastened on a $3 \mathrm{~mm}$ thick copper plate and covered with the ECH shield. The pickup coil was either terminated by a $R_{L}=50 \Omega$ load or left open, and then connected directly to an oscilloscope. The sensor was wrapped using Kapton ${ }^{\circledR}$ tape during the measurement in order to avoid accidental electric contact between the coil and the copper plate. The experimental results are shown in Figure 18. The ECH shield was seen to 
exert no impact on the frequency response of coil's sensitivity up to $1 \mathrm{MHz}$. In addition, the ECH shield was also found not to affect coil's complex impedance, as shown in Appendix 3.

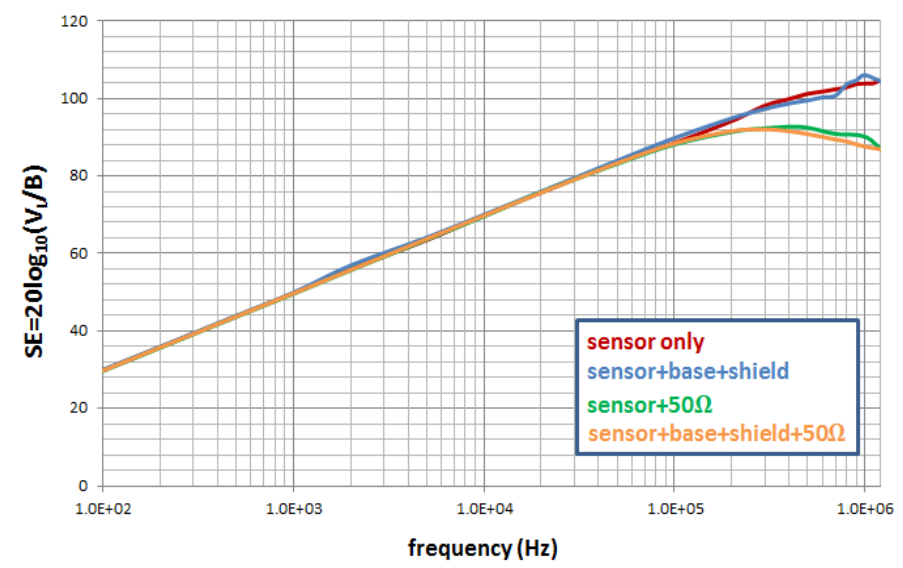

Figure 18: comparison of the output sensitivity of HF sensor with and without the ECH shield.

\subsection{Stray microwave radiation test}

The stray microwave irradiation test was intended to examine the performance (shielding efficiency) of the shield, and verify the structural integrity of the ECH shield as well as the coating under high thermal stress generated by microwave heating. This test was conducted in the MISTRAL (MIcrowave STray RAdiation Launch) facility at IPP-Greifswald. Microwave generated by a gyrotron source was injected into the vacuum chamber of MISTRAL through the aperture at the bottom of the device. Injected microwave power was fixed at $180 \mathrm{~kW}$ with frequency at $140 \mathrm{GHz}$, close to the ITER ECH frequency which is at $170 \mathrm{GHz}$. The test consisted of two experiments:

1. Stray radiation experiment to measure the shielding efficiency in a stray radiation field;

2. Direct-beam experiment to verify the structural integrity of the shield body as well as the titanium coating in exposure to high microwave power density up to $3 \mathrm{MW} / \mathrm{m}^{2}$ (i.e., the highest stray ECH power density foreseen during ITER operation).

In the first experiment, a beam splitter was placed near on top of the aperture to guide the input beam around the edge of the aluminum vacuum chamber and create a uniform stray radiation field in the center by scattering the beam at each reflection ([15]). The gyrotron throughout this experiment was configured to generate microwave pulses with $5 \mathrm{~ms}$ duration (per pulse) and modulated at 1:18 duty cycle, i.e. the microwave was on for $5 \mathrm{~ms}$ and then off for $85 \mathrm{~ms}$. Time averaged microwave power density derived from a bolometer measurement was approximately $40 \mathrm{~kW} / \mathrm{m}^{2}$. Pickup coil and ECH shield were fastened to the stainless steel baseplate (see Figure 14) using simple bolt joints (spring washers were not applied), therefore thermal conduction was expected to be poor. Thermocouples were placed inside the coil body (a hole was drilled in the coil bobbin to allow the insertion), as well as on the inner and outer surface of the shield. The installed assembly was placed inside the vacuum chamber ready for radiation test. 

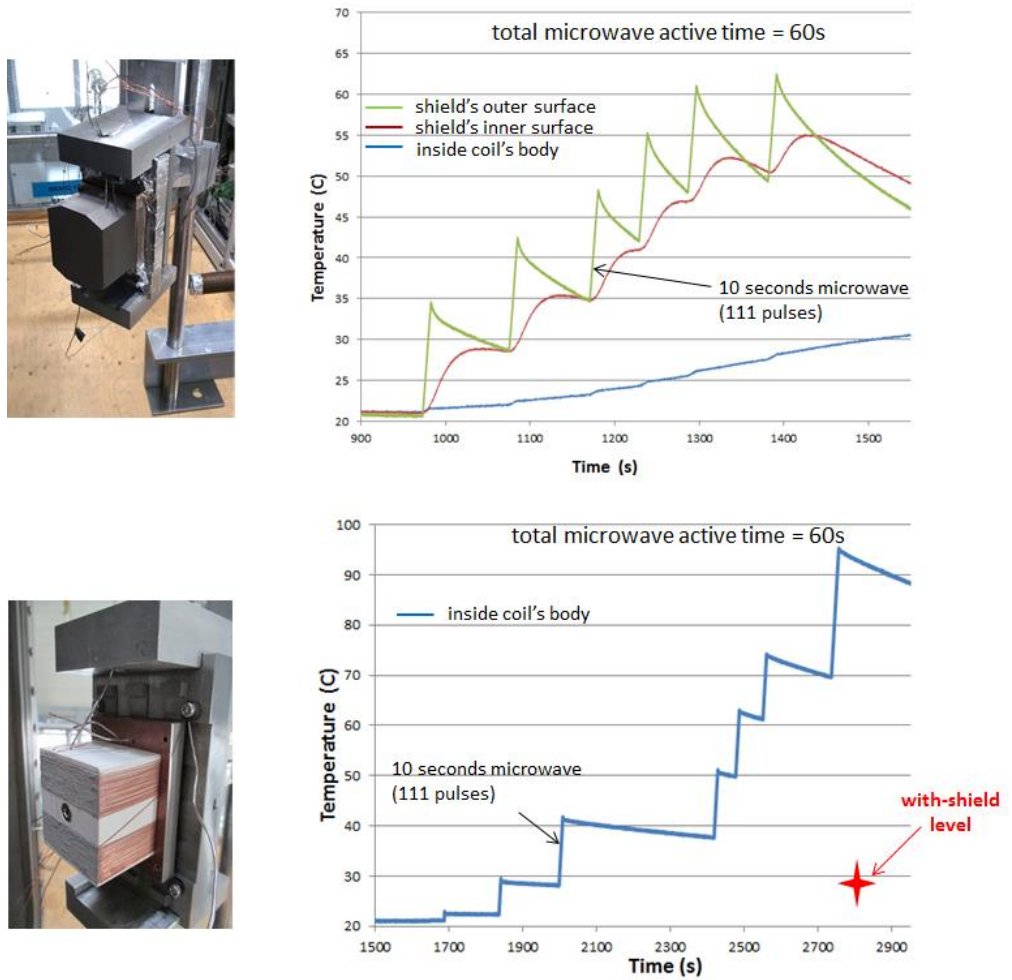

Figure 19: stray radiation experiment with (left) test components assembly with and without shield; (right) temperature measurement by thermocouples with and without the shield.

Temperatures measured by the thermal couple inside the coil bobbin with and without the ECH shield were compared to derive the shielding efficiency. Results are shown in Figure 19. With the shield, the temperature increased by about $0.5^{\circ} \mathrm{C}$ in 10 seconds (i.e., with 111 microwave pulses). Without the shield, temperature increased by about $15^{\circ} \mathrm{C}$ with the same number of pulses. This suggests that the shielding efficiency is $0.5 / 15=1 / 30$. The accumulative effect is more severe: without the shield, temperature rose to $\sim 100^{\circ} \mathrm{C}$ after six consecutive 10 seconds irradiation periods (in total 666 pulses, or 3.3 seconds of microwave), while with the shield, the temperature was contained at about $30^{\circ} \mathrm{C}$, or less than $10^{\circ} \mathrm{C}$ increase. The results confirm the necessity of the $\mathrm{ECH}$ shield in protecting the pickup coil from microwave heating, especially in long-term events like ITER long-pulse plasma operation.
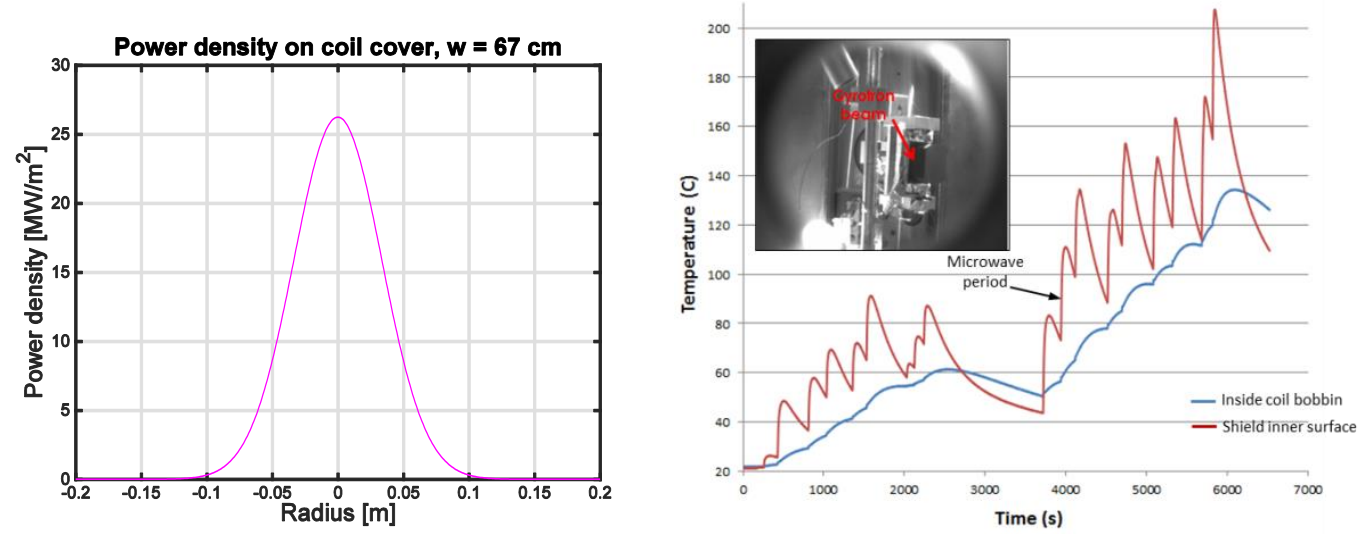

Figure 20: direct-beam experiment with (left) instantaneous microwave beam power density distribution on shield surface; (right) beam incident direction and temperature measurement by thermocouples (note the thermal couple inside the shield was attached to the top surface therefore not on the beam path). 
The setup was adapted in the second (direct-beam) experiment to help achieve the demanded high power density of $3 \mathrm{MW} / \mathrm{m}^{2}$. The beam splitter was removed and a microwave mirror was installed inside the chamber to reflect the input Gaussian beam on to the outer surface of the ECH shield. The incident direction of the beam and calculated instantaneous beam power density distribution on the shield's surface are shown in Figure 20. The peak value was about $28 \mathrm{MW} / \mathrm{m}^{2}$, about 10 times of the target. The FWHM (Full Width at Half Maximum) beam waist was approximately $10 \mathrm{~cm}$. Duty cycle varied from 1:18 at the beginning of the experiment, to 1:5 at the end. Consequently, time-averaged peak power density increased from $1.6 \mathrm{MW} / \mathrm{m}^{2}$ to $5.6 \mathrm{MW} / \mathrm{m}^{2}$. For safety concern, the shield was covered throughout this experiment to protect the pickup coil from being direct illuminated by the dramatically high-power gyrotron beam. In total 17 shots were obtained. The sum duration was 80 seconds, among which 7.0 seconds were with microwave power. Figure 20 shows that the thermal couple inside the coil measured $2-4^{\circ} \mathrm{C}$ temperature increase in a 5.0 seconds shot. Accumulated heating elevated the coil's temperature to approximately $130^{\circ} \mathrm{C}$ at the end of the experiment, still well within the working temperature range of Shapal-M (maximum use temperature for Shapal-M is $\left.1900^{\circ} \mathrm{C}\right)$.

A video camera was operated in the direct-beam experiment and captured images when shield was blasted by the microwave beam. Some images were gathered and displayed in Figure 21. Several bright dots (minor arcing) were noticed on the shield surface when peak power density was at $2.8 \mathrm{MW} / \mathrm{m}^{2}$ (1:10 duty cycle). These dots correspond to the position markers on the shield surface left from manufacturing. Therefore, they are the cause rather than the consequence of the arcing. The shield surface began to glow when peak power density exceeded $4.0 \mathrm{MW} / \mathrm{m}^{2}$. The prototypes were carefully inspected after the experiment. No damage or crack was discovered. Bolt joints remained tight, and coating on the shield remained complete with no sign of melting or flaking. Photographic surveys before and after the test are compared in Figure 21, showing no evident difference. The results verify the robustness of the shield design when exposed to high power microwave radiation.
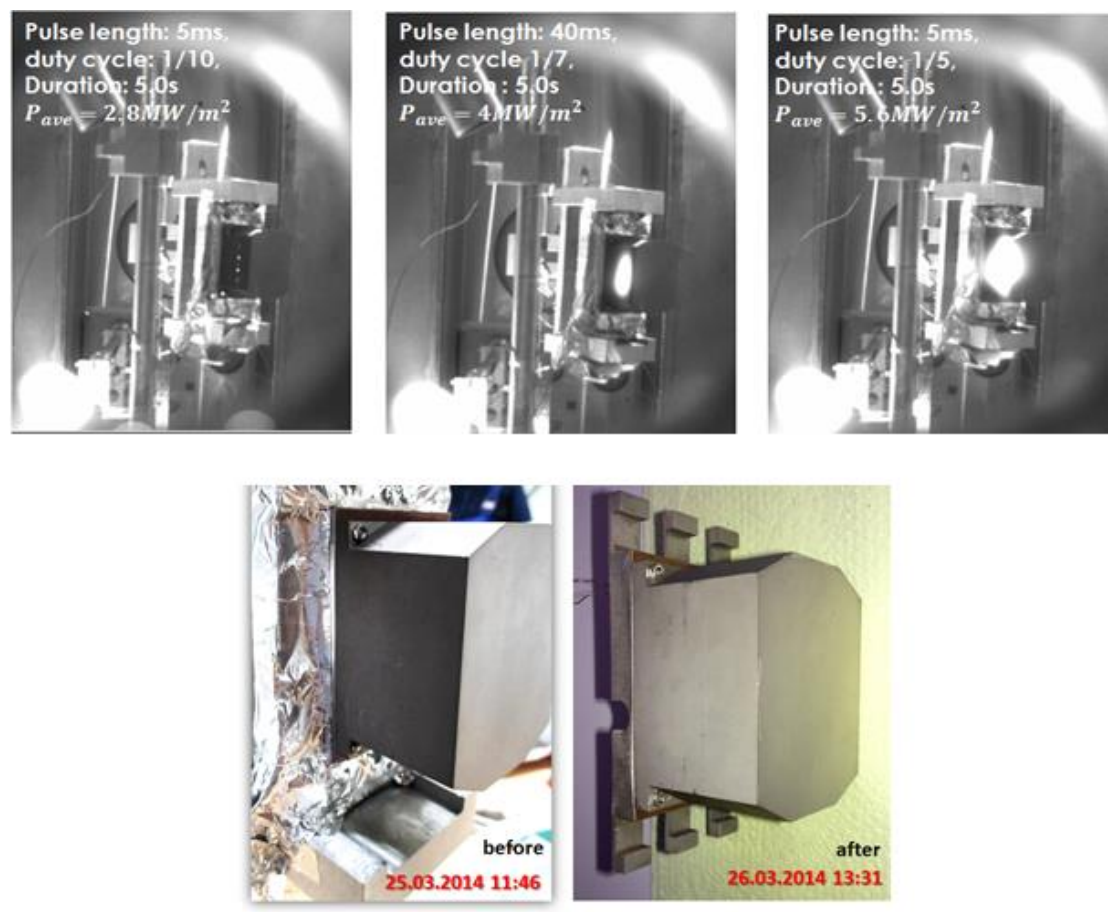

Figure 21: (top) video camera images taken in the direct-beam experiment; (bottom) photos of the assembly taken before and after the test. 
It is noticed that the measured attenuation factor $(\sim 1 / 30$, or $15 \mathrm{~dB}$ according to the definition in Table 3 ) yielded by the ECH shield is significantly lower compared to the theoretical value of $\sim 80 \mathrm{~dB}$ (see Table 3). Despite this deficiency, the shield has been demonstrated to effectively protect the pickup coil from overheating and thermal shocks in practical application, and proved to be an indispensable component for the HF sensor system in long term operation. Subsequent research activities (Section 5.4, Section 5.5) primarily focused on understanding the reason for the discrepancy.

\subsection{Low-power microwave attenuation measurement}

The microwave attenuation measurement was conducted in the electronics lab at TU/e following the completion of the stray microwave irradiation test. The aim of this measurement is to carefully examine the single-pass microwave attenuation generated by individual surfaces of the ECH shield. To set up the measurement, a surface of a ECH shield prototype was tightly sandwiched by two waveguides, one broadcasting microwaves at $60 \mathrm{GHz}$ from one side and the other receiving on the other side, as shown in Figure 22. A piece of paper was inserted between a waveguide and the surface of the shield to prevent spurious waves arising from multi-reflections. A type PNA-X Keysight ${ }^{\circledR}$ network analyzer was utilized to record data.

The top surface and one of the side surfaces of the shield were inspected. Measurement results found that the top surface produced more than $70 \mathrm{~dB}$ attenuation, but only about $17 \mathrm{~dB}$ attenuation (i.e. a factor of 1/50 decay) was generated by the side surface. The finding suggests that the side surfaces are major sources of leakage that led to the much lower (than expected) shielding efficiency observed earlier in the stray radiation experiment. This is probably because the actual coating layer deposited on the side surfaces might not be sufficiently thick (much below the design target $5 \mu \mathrm{m}$ ) to effectively block the ECH waves, possibly due to deficiencies associated with the static PVD coating technique (as also noted by the supplier that the coating was not uniform and thinner on the sides with $3.6 \mu \mathrm{m}$ estimated thickness, see Chapter 4), and/or some chemical process (e.g. oxidation, corrosion, etc.) that may degrade the quality and effectiveness of the coating. Rough surface finish of the ceramic substrate and sharp edges/corners are also potential causes of microwave leakage. A suggested direction for future production is to practice stricter quality control on coating techniques and procedures, including more accurate thickness control and verification, and enhanced quality assurance (e.g. substrate surface roughness control, sharp edges/corners removal, degradation and wear resistance, etc.).
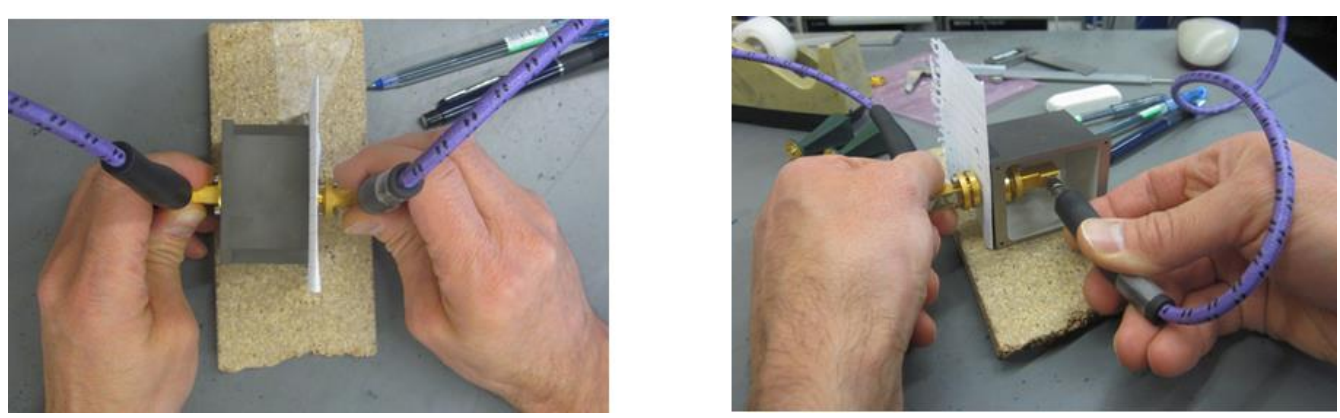

Figure 22: microwave $(60 \mathrm{GHz})$ attenuation measurement using waveguides on (left) the top surface, (right) a side surface of the ECH shield. 


\subsection{SEM inspection of the coating}

Scanning electron microscope (SEM) inspection of the ECH shield was conducted at IPP Prague to unveil the microstructure of the coating. The top surface of the shield was probed in this study. Figure 23 includes images of surface profile of the titanium coating. The deposition profile looks typical as that routinely obtained using the PVD technique. Images taken at various locations (not shown) verify the integrity of the coating across the bulk area of the surface. Only near the immediate edge was some minor flaking of the titanium coating discovered. Unfortunately, thickness of the coating layer could not be directly retrieved from the SEM images. Yet, examining the edge where coating was found peeled off, it implies that the coating on the side surface might be very thin in this region, possibly $\sim 2 \mu \mathrm{m}$ or even less (i.e., only $\sim 2$ times the skin depth at $170 \mathrm{GHz}$ ). This might explain the shield's poor attenuation of ECH power in the MISTRAL tests. Another SEM inspection carried out by MEPhI probed a side surface of the shield and obtained similar surface profile images, shown in Figure 23 (c). Final ECH shield production should avoid sharp edges to reduce the risk of damaging the coating during assembly and/or long-term use.
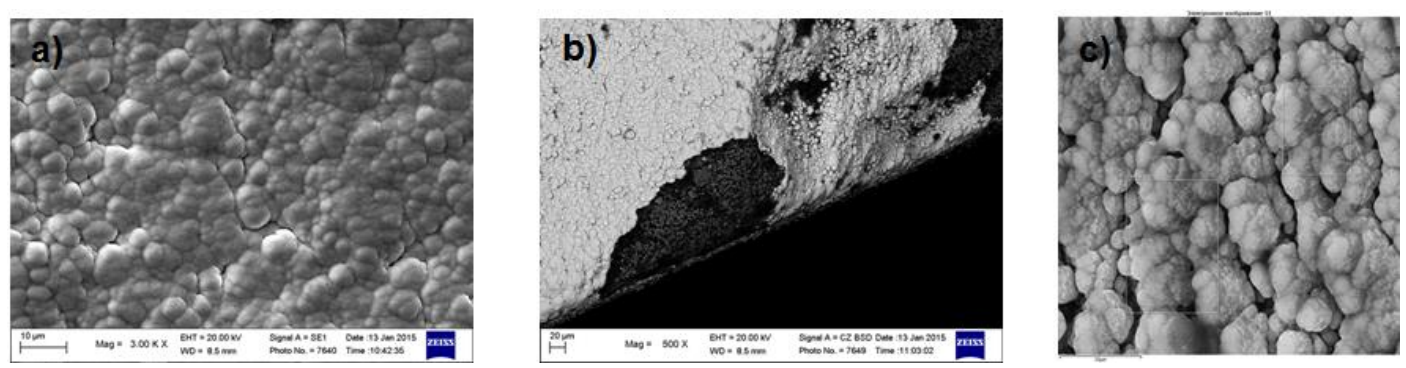

Figure 23: SEM images of the titanium coating on the ECH shield: (a) near the middle of the top surface, (b) edge of the top surface, (c) on the side surface. [courtesy of IPP Prague: (a) and (b), and MEPhI: (c)]

\section{Project status and ongoing work}

ITER HF sensor system has undergone Preliminary Design Review (PDR) held at ITER Organization in May 2014 and is now leading to the Final Design. Continuous R\&D activities focus on addressing the outstanding technical issues raised on the PDR. A task has been initiated to produce ECH shield with quality conductive coating of uniform thickness, strong adhesion, and good chemical and thermal shock resistance. There are ongoing efforts to improve the design of the mechanical support structure for the sensor allowing it to withstand the high thermal and EM loads inside ITER VV, and to be compatible with various functional requirements (e.g. remote handling). An integrated thermal mechanical analysis on the entire sensor assembly is in progress. Fast prototyping of the sensor support structure has been planned and will be initiated in the near future. Welding and assembly test will be performed subsequently. The aim of these undertakings is to deliver a sound basis for the project to proceed to the final design.

\section{Conclusions}

ITER high-frequency inductive magnetic sensor system, including pickup coil, ECH shield, and electric cabling, has been designed to meet the measurement and integration requirements. Prototypes of these components have been fabricated and tested. The testing verified that the frequency response and thermal performance of the system is consistent with the design target. Microwave radiation test validated the robustness of the shield design under high microwave induced thermal stress, and demonstrated the validity and necessity of the ECH shield in protecting the coil from overheating and 
thermal shocks in practical applications, despite the measured shielding efficiency exhibited large discrepancy with the theoretical prediction. Subsequent low-power microwave attenuation measurement and SEM inspection somehow suggested that side surfaces and sharp edges of the shield could be the main sources of microwave leakage in the MISTRAL tests, probably because the coating layer deposited on these surfaces was not sufficiently thick (relative to the design target) to effectively block the ECH waves. Future design improvement will focus on producing quality coating with more accurate thickness and uniformity control and verification, and enhanced quality assurance.

\section{Acknowledgement}

The authors acknowledge the Special Technique Group of CCFE for fabrication of prototypes of the pickup coil and the ECH shield, Hanspeter Marti for producing the prototypes of the mounting baseplate, Juan Alfaro of TU/e for conducting the microwave attenuation measurement, Rein Rumphorst of TU/e for measuring the electrical properties of pickup coil, Radek Musalek of IPP Prague for assisting in the SEM inspection.

The views and opinions expressed herein do not necessarily reflect those of the ITER Organization.

\section{Reference}

[1] A.Rizzolo, Electro-mechanical connection system for ITER in-vessel magnetic sensors, Fusion Engineering and Design, doi:10.1016/j.fusengdes.2016.03.027

[2] A.C.Neto, Conceptual architecture of the plant system controller for the magnetics diagnostic of the ITER tokamak, Fusion Engineering and Design, Volumes 96-97, October 2015, Pages 887890

[3] A.J.H.Donne et al. Progress in ITER Physics Basis - Diagnostics, Nuclear Fusion , 47 (6), 2007

[4] J. Gonzalez, Distribution of the In-Vessel Diagnostics in ITER Tokamak, to be submitted to the 12th International Symposium on Fusion Nuclear Technology

[5] F. Grover F, Inductance Calculations, Dover (2009), pp. 71-72

[6] M. Kazimierczuk, High-frequency magnetic components, Wiley (2009), Ch9.8.

[7] T.Yano et al, Journal of Nuclear Materials 179-181 (1991) 387-390

[8] T.Yano et al, Journal of Nuclear Materials 283-287 (2000) 947-951

[9] J.W.Oosterbeek et al, Loads due to Stray Microwave Radiation in ITER, Fusion Engineering and Design, Volumes 96-97, October 2015, Pages 553-556

[10] K.Kaiser, Electromagnetic Compatibility Handbook, CRC Press 2005

[11] R.E.Collin, Foundations for Microwave Engineering ( $2^{\text {nd }}$ edition), IEEE Press, 200, pp.117

[12] J. T. Bevans, Prediction of Space Vehicle Thermal Characteristics, Air Force Flight Dynamic Laboratory Technical Report AFFDL-TR-65-139, August 1965.

[13] M. Yovanovich, Spacecraft radiative transfer and temperature control, Vol. 83, Progress in Astronautics and Aeronautics, AIAA, New York, 1982, pp. 83-95

[14] M. Bahrami, Review of Thermal Joint Resistance Models for Nonconforming Rough Surfaces, Applied Mechanics Reviews, Vol. 59, 2006

[15] M. Hirsch et al, "The Impact of Microwave Stray Radiation to In-Vessel Diagnostic Components" AIP Conference Proceedings 1612, 39 (2014), doi: 10.1063/1.4894022 


\section{Appendix 1. Summary of prototypes lab testing}

\begin{tabular}{|c|c|c|c|c|c|c|}
\hline & $\begin{array}{c}\text { CCFE (Special } \\
\text { Technique Group) }\end{array}$ & CEA & TU/e & $\begin{array}{c}\text { IPP-Greifswald } \\
\text { (MISTRAL Facility) }\end{array}$ & MEPhl & IPP-Prague \\
\hline HF-Coil-01 & $\begin{array}{c}\text { ASSEM, VTC, TCC, } \\
\text { RLC }\end{array}$ & RLC, FRES, TCC & & & & \\
\hline HF-Coil-02 & $\begin{array}{l}\text { ASSEM, VTC, TCC, } \\
\text { RLC }\end{array}$ & & RLC,FRES & & & \\
\hline HF-Coil-03 & $\begin{array}{c}\text { ASSEM, VTC, TCC, } \\
\text { RLC }\end{array}$ & & & MW-ATT (HP) & & \\
\hline HF-Shield-01 & ASSEM, VTC, TCC & RLC, FRES, TCC & & & & \\
\hline HF-Shield-02 & ASSEM, VTC, TCC & & $\begin{array}{l}\text { MW-ATT (LP), } \\
\text { RLC,FRES }\end{array}$ & & & \\
\hline HF-Shield-03 & ASSEM, VTC, TCC & & & MW-ATT (HP) & & \\
\hline HF-Shield-04 & & & & & SEM-ANALY & \\
\hline HF-Shield-05 & & & & & & SEM-ANALY \\
\hline HF-Silica-MIC & & FRES & & & & \\
\hline \multicolumn{7}{|c|}{$\begin{array}{l}\text { ASSEM : Assembly Test (Section 5.1) } \\
\text { VTC : Vacuum Thermal Cycling (Section 5.1) } \\
\text { TCC : Thermal Contact Conductance (Section 5.1) } \\
\text { RLC : RLC (electrical characteristics) measurement of the coil (Section 5.2) } \\
\text { FRES : Frequency Response measurement (Section 5.2) } \\
\text { MW-ATT (HP) : High-Power Microwave Attenuation measurement (Section 5.3) } \\
\text { MW-ATT (LP) : Low-Power Microwave Attenuation measurement (Section 5.4) } \\
\text { SEM-ANALY : Scanning Electron Microscope Analysis of metal coating (Section 5.5) }\end{array}$} \\
\hline
\end{tabular}

Table A1 : Summary of the testing/inspections for each prototype performed at various research institutes

\begin{tabular}{|c|c|c|c|c|c|c|c|}
\hline & $\begin{array}{c}\text { CCFE (Special } \\
\text { Technique Group) }\end{array}$ & CEA & TU/e & $\begin{array}{c}\text { IPP-Greifswald } \\
\text { (MISTRAL Facility) }\end{array}$ & MEPhl & IPP-Prague \\
\hline \multicolumn{2}{|c|}{ ASSEM } & Pass & & & & & \\
\hline \multicolumn{2}{|c|}{ VTC } & Pass & & & & & \\
\hline \multirow{2}{*}{ TCC } & $\begin{array}{l}\text { Coil-Cu } \\
\text { plate }\end{array}$ & $1.2 \mathrm{~W} / \mathrm{K}$ & & & & & \\
\hline & $\begin{array}{c}\text { Shield-Cu } \\
\text { plate }\end{array}$ & $0.3 \mathrm{~W} / \mathrm{K}$ & $0.33 \mathrm{~W} / \mathrm{K}$ & & & & \\
\hline \multicolumn{2}{|r|}{ RLC } & $\mathrm{R}=0.8 \Omega$ & $\begin{array}{l}\mathrm{R}=0.788 \Omega \\
\mathrm{L}=42.4 \mu \mathrm{H} \\
\mathrm{C}=44.5 p \mathrm{~F}\end{array}$ & $\begin{array}{l}\mathrm{L}=44 \mu \mathrm{H} \\
\mathrm{C}=35 \mathrm{pF}\end{array}$ & & & \\
\hline \multicolumn{2}{|c|}{ FRES } & & $\begin{array}{l}\text { ECH shield no impact } \\
\text { on coil's response up } \\
\text { to } 1 \mathrm{MHz} \text {; System's } \\
\text { frequency response } \\
\text { match the prediction }\end{array}$ & $\begin{array}{l}\text { ECH shield no } \\
\text { impact on coil's } \\
\text { response up to } \\
1 \mathrm{MHz}\end{array}$ & & & \\
\hline \multicolumn{2}{|c|}{ MW-ATT (HP) } & & & & $\begin{array}{c}\text { Overall } \\
\text { attenuation by } \\
\text { ECH shield @ } \\
140 G \mathrm{Gz}=1 / 30, \\
\text { shield and coil } \\
\text { survived }\end{array}$ & & \\
\hline \multicolumn{2}{|c|}{ MW-ATT (LP) } & & & $\begin{array}{c}>70 \mathrm{db} \\
\text { attenuation by top } \\
\text { surface and } 17 \\
\mathrm{db} \text { by side surface } \\
@ 60 \mathrm{GHz} \\
\end{array}$ & & & \\
\hline \multicolumn{2}{|c|}{ SEM-ANALY } & & & & & $\begin{array}{l}\text { Coating surface } \\
\text { profile normal } \\
\text { for PVD } \\
\text { technique }\end{array}$ & $\begin{array}{l}\text { Coating surface } \\
\text { profile normal for } \\
\text { PVD technique, } \\
\text { side surface } \\
\text { thickness could } \\
\sim<2 \mu \mathrm{m}\end{array}$ \\
\hline
\end{tabular}

Table A2 : Summary of key results obtained from the prototypes testing 


\section{Appendix 2. Impedance measurement of HF pickup coil}

The resistance and inductance of the pickup coil prototype HF-Coil-01 (naming convention according to Table A1) were measured in the electronics lab of CEA. The resistance was directly measured using both a multimeter and an impedance meter (MOTECH® model 4090). The inductance was directly measured using the MOTECH ${ }^{\circledR}$ model 4090 impedance meter at 6 different frequencies ranging from $100 \mathrm{~Hz}$ to $200 \mathrm{kHz}$, and also deduced from the cut-off ( $3 \mathrm{db}$ attenuation) frequency measurement of an RL network. The results are summarized in Table A3.

\begin{tabular}{l|lll}
\hline Parameter & Device & Setup & measurement \\
\hline Resistance & Impedance Meter MOTECH 4090 & DCR, 4 wires & $0.788 \Omega$ \\
& Multimeter Fluke 8840A & auto, 2 wires & $0.800 \Omega$ \\
& Inductance & & \\
& & $\mathrm{L}_{\mathrm{s}}, 4$ wires, $100 \mathrm{~Hz}$ & $42.44 \mu \mathrm{H}$ \\
& $\mathrm{L}_{\mathrm{s}}, 4$ wires, $120 \mathrm{~Hz}$ & $42.50 \mu \mathrm{H}$ \\
& $\mathrm{L}_{\mathrm{s}}, 4$ wires, $1 \mathrm{kHz}$ & $42.40 \mu \mathrm{H}$ \\
& $\mathrm{L}_{\mathrm{s}}, 4$ wires, $10 \mathrm{kHz}$ & $42.45 \mu \mathrm{H}$ \\
& $\mathrm{L}_{\mathrm{s}}, 4$ wires, $100 \mathrm{kHz}$ & $42.41 \mu \mathrm{H}$ \\
& & $\mathrm{L}_{\mathrm{s}}, 4$ wires, $200 \mathrm{kHz}$ & $42.35 \mu \mathrm{H}$ \\
& & & \\
& LR network: & $\mathrm{R}_{\mathrm{s}}=100.21 \Omega$, & $41.55 \mu \mathrm{H}\left(\mathrm{f}_{3 \mathrm{db}}=383 \mathrm{kHz}\right)$ \\
& Function generator HAMEG HM8030, & $\mathrm{R}_{\mathrm{s}}=51.4 \Omega$ & $41.90 \mu \mathrm{H}\left(\mathrm{f}_{3 \mathrm{db}}=195.2 \mathrm{kHz}\right)$ \\
\hline
\end{tabular}

Table A3 : Summary of resistance and inductance measurement results for coil HF-Coil-01

Similar exercise was practiced for the pickup coil HF-Coil-02 in the electronics lab at TU/e. The experimental setup was illustrated in Figure A1. The coil was pressed on a copper plate in the measurement. A train of $4 \mathrm{MHz}$ waves was sent to the T-network. Coil's inductance and capacitance was derived by fitting to the damped harmonic waves detected at the output end. The measurement suggested that $L=44 \mu H$ and $C=35 p F$, which are consistent with those for HF-Coil-01.

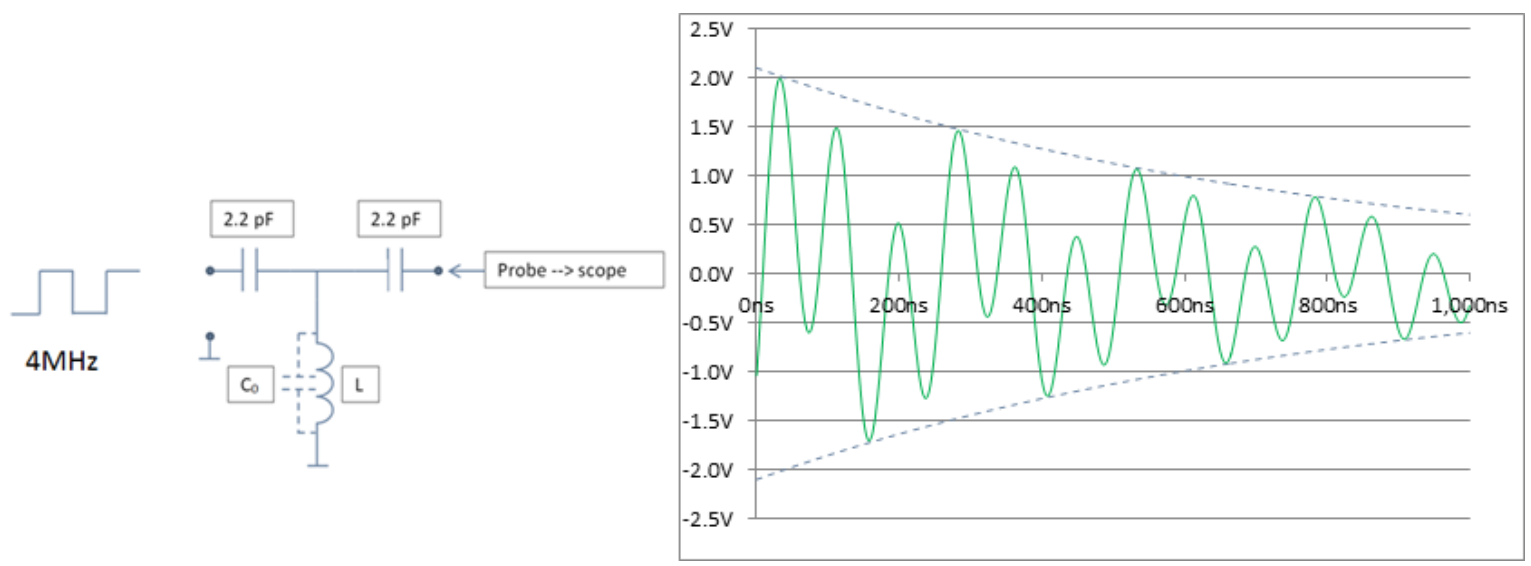

Figure A1 : Experimental setup for the impedance measurement of HF-Coil-02 and the measured output signals 


\section{Appendix 3. Frequency dependence of HF pickup coil electrical properties}

The effective area (NA) and complex impedance $\left(Z_{c o i l}=R_{c}+j \omega L_{c}\right)$ of coil was obtained from the frequency response measurement performed at CEA with the experimental setup illustrated in Figure A2. The oscilloscope (DSO) was tuned to operate at $1 \mathrm{M} \Omega$, AC mode and $30 \mathrm{MHz}$ low-pass filtering.

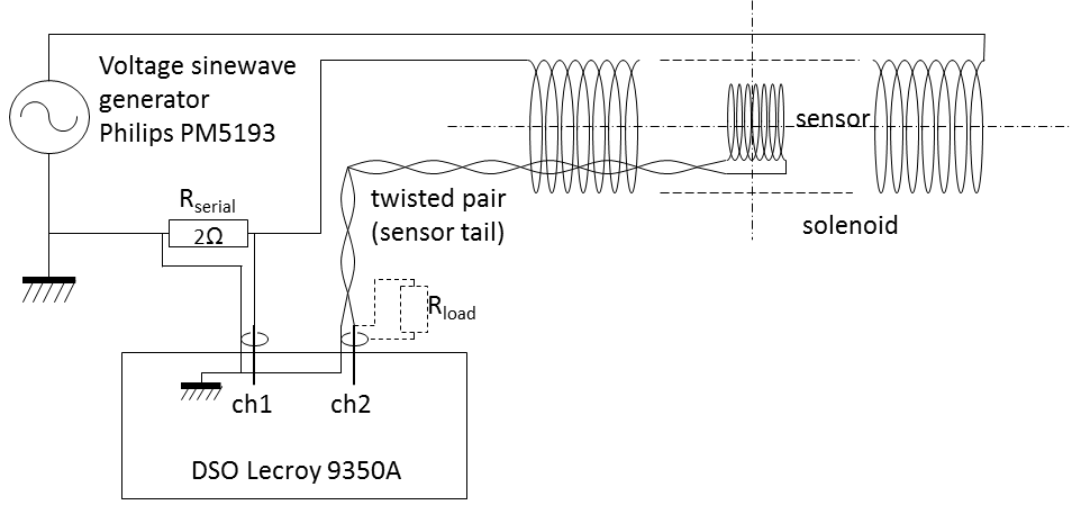

Figure A2: Experimental setup for frequency response measurement of HF pickup coil (HF-Coil-01) at CEA

The effective area was derived from measurements with the pickup coil directly connected to DSO, and according to the relation $N A(f)=V_{\text {out }} / 2 \pi f B$. Three scenarios were examined: (1) coil only, (2) coil and baseplate (3mm thick Glidcop ${ }^{\circledR}$ copper), (3) copper, baseplate and ECH shield. The results are shown in Figure A3. The data suggest that NA of the pickup coil (without shield or baseplate) is maintained largely between $0.045 \mathrm{~m}^{2}$ and $0.05 \mathrm{~m}^{2}$ (i.e. $0.048 \mathrm{~m}^{2} \pm 5 \%$ ) up to $500 \mathrm{kHz}$. The ECH shield and the copper baseplate have no clear impact on coil's effective area (perhaps a minor $\sim 10-15 \%$ reduction above $300 \mathrm{kHz})$.
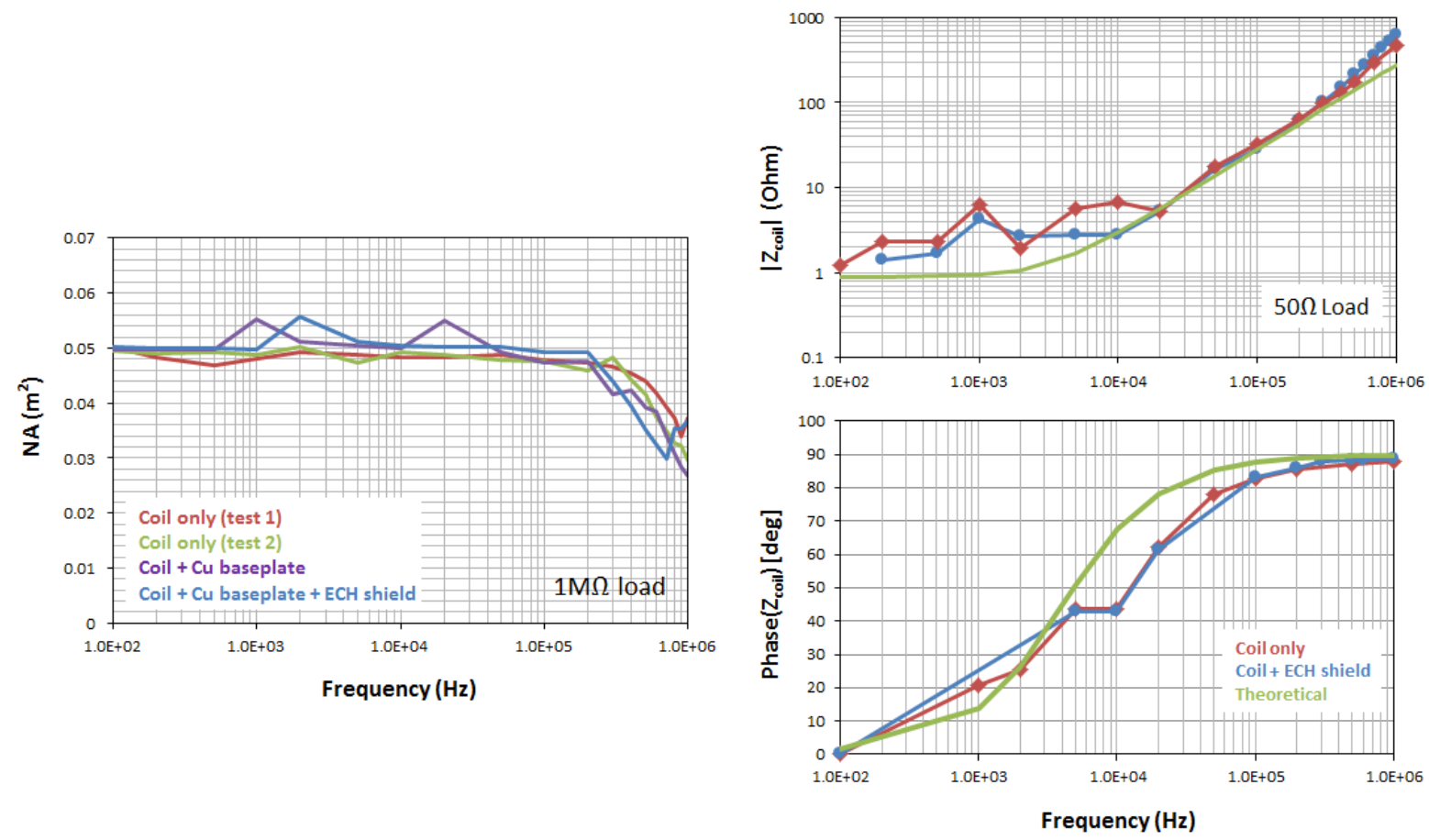

Figure A3: Frequency dependence of the HF pickup coil's (left) effective area, (right top) magnitude of the complex impedance, (right bottom) phase of the complex impedance, measured using prototypes HF-Coil-01 and HF-Shield-01 with the setup shown in Figure A2. 
The complex impedance of the pickup coil was obtained from measurements with $R_{\text {load }}=50 \Omega$, deduced using the relation $V_{o}=(N A)_{D C} \times(j \omega B) \times R_{\text {load }} /\left(R_{\text {load }}+Z_{\text {coil }}\right)$. Two scenarios were examined: (1) coil only, (2) coil, baseplate and ECH shield. Results are shown in Figure A3, suggesting that ECH shield has no clear impact on the coil's complex impedance. Theoretical values of the coil's complex impedance are also displayed for reference.

The influence of ECH shield on the frequency response of pickup coil was also investigated in the electronics lab of TU/e with similar measurement setup as in Figure A2. The coil (HF-Coil-02) was seated on the steel platform (see Fig.14) and placed outside and near a solenoid. The output voltage was measured with and without the shield (HF-Shield-02) at various frequencies ranging from $10 \mathrm{kHz}$ to $1 \mathrm{MHz}$, as shown in Figure A4. It is seen that the shield has no clear impact on the coil.

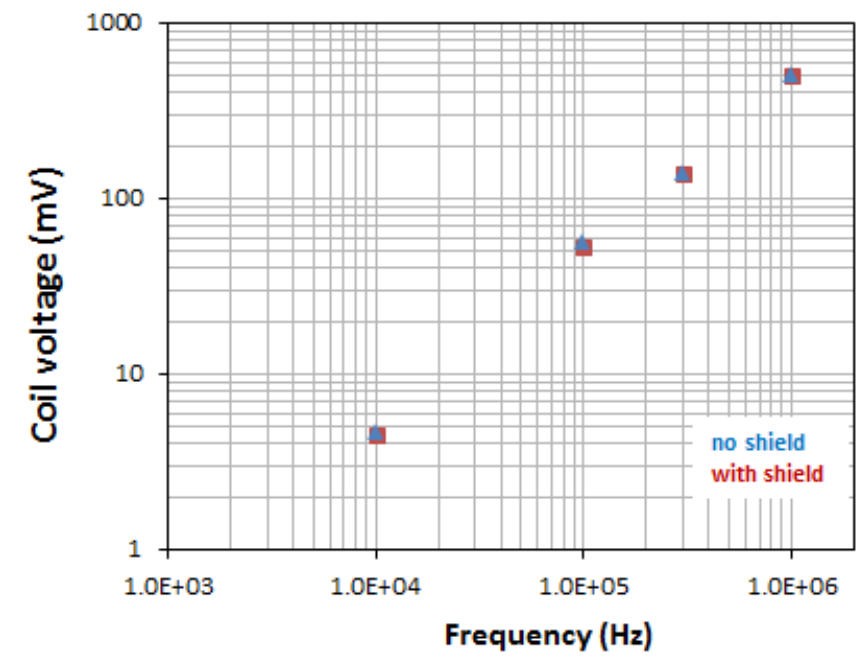

Figure A4: Output voltage of the pickup coil with and without the application of the ECH shield at various frequencies (measured in the electronics lab at TU/e using prototypes HF-Coil-02 and HF-Shield-02) 


\section{Appendix 4. Frequency-domain response of an LTCC coil}

The concept of using LTCC (Low-Temperature Co-fired Ceramic) sensors for ITER HF magnetic measurement is of academic and practical interest and therefore has been explored. The study suggested that within the available space allocation, the largest LTCC sensor that could potentially meet the design target of $A_{e f f}=N A \geq 0.05 \mathrm{~m}^{2}$ has the following mechanical and electrical specifications:

\begin{tabular}{|c|c|}
\hline turn radius & $2 \mathrm{~cm}$ \\
\hline pitch (turn-turn distance) & $0.25 \mathrm{~mm}$ \\
\hline number of turns & 40 \\
\hline coil thickness & $\sim 1 \mathrm{~cm}$ \\
\hline coil volume & $\sim 12 \mathrm{~cm}^{3}$ \\
\hline$N A$ & $0.05 \mathrm{~m}^{2}$ \\
\hline$L$ & $90 \mu \mathrm{H}$ \\
\hline$R_{C}\left(\mathrm{DC}, 20^{\circ} \mathrm{C}\right)$ & $40 \Omega$ \\
\hline
\end{tabular}

Table A4 : Mechanical and electrical characteristics of an LTCC sensor with NA=0.05 $\mathrm{m}^{2}$ and of the largest size within the available space allocation.

The high impedance nature of LTCC sensor leads to unfavourable frequency-domain response in real application with loading network (transmission lines and termination load, refer to Table 5) connected. In the "matched" configuration (ex-vessel line balanced by a $120 \mathrm{Ohm}$ load, Table 5), the output voltage, as shown in Figure A5, cut off (attenuated by $3 \mathrm{db}$ ) at about $150 \mathrm{kHz}$, and then droop rapidly to less than $40 \%$ of the coil induced voltage at $500 \mathrm{kHz}$. Comparatively, the $3 \mathrm{db}$ cut-off frequency in the same termination configuration with the wound coil is approximately $600 \mathrm{kHz}$, above the $500 \mathrm{kHz}$ upper bound of the measurement range. It is even worse in the "open" configuration $\left(R_{L}=1 \mathrm{G} \Omega\right.$, Table 5 ), where the first frequency-domain resonance, as shown in Figure A5, remains and occurs at a lower frequency of about $150 \mathrm{kHz}$, while the second resonance is found near $500 \mathrm{kHz}$. Therefore, the LTCC sensor could not produce desired frequency response with real loading network in connection, and for this reason it is not opted for ITER HF pickup coil.
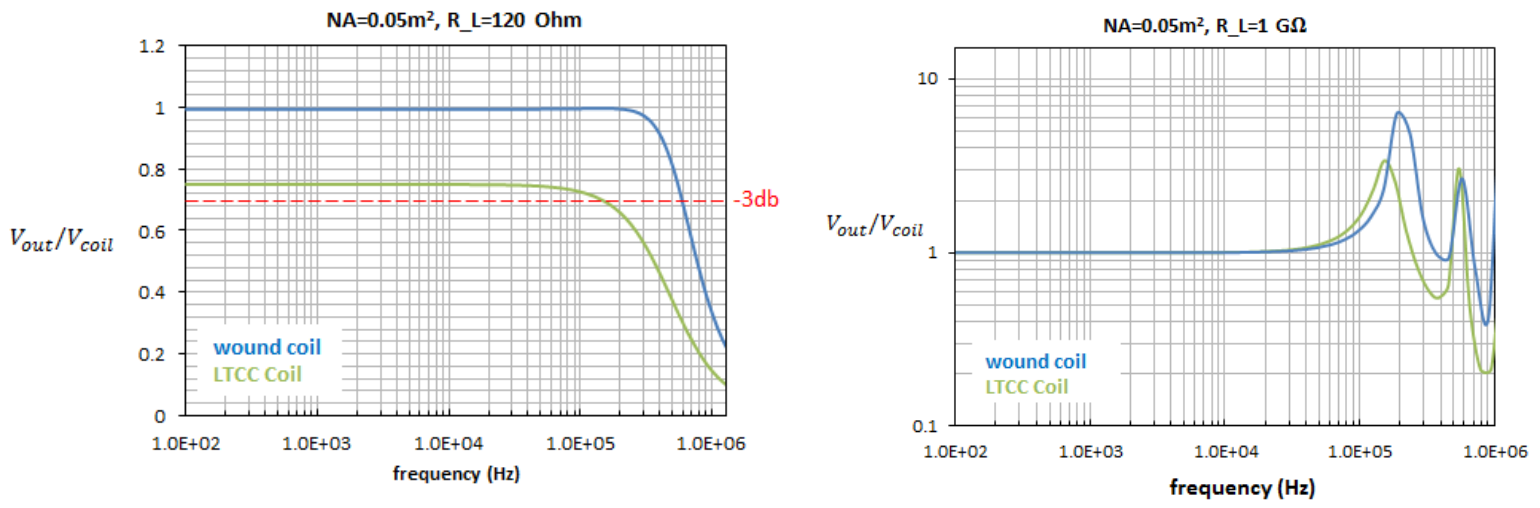

Figure A5 : Frequency-domain response of the output to coil-induced voltage ratio for an LTCC sensor with $0.05 \mathrm{~m}^{2}$ effective area (ref. Table $A 4)$ in (left) matched $\left(R_{L}=120 \Omega\right)$, and (right) open $\left(R_{L}=1 G \Omega\right)$ termination scheme according to Table 5, in comparison with the conventional wound coil (ITER HF pickup coil design, Table 2). 